\title{
The Effect of Interface Morphology on the Electro-Mechanical Properties of Ti/Cu Clad Composites Produced by Explosive Welding
}

\author{
HENRYK PAUL, WOJCIECH SKUZA, ROBERT CHULIST, \\ MAGDALENA MISZCZYK, ALEKSANDER GAŁKA, MARIUSZ PRAŻMOWSKI, \\ and JANUSZ PSTRUŚ
}

\begin{abstract}
The effect of interfacial microstructure on the electro-mechanical properties of explosively welded titanium and copper plates is discussed. Mechanical testing proved that using detonation velocities ranging from 2000 to $3000 \mathrm{~m} \mathrm{~s}^{-1}$ and stand-off distances from 1.5 to $9.0 \mathrm{~mm}$, joints that satisfy the strength criteria for a good quality clad were produced. Scanning electron microscopy images show that all interfaces exhibit a wave character. It was noticed that as the stand-off distances and detonation velocities increase, the amplitude and period of the waves, as well as the quantity of the melt zones, increase as well. Also, as the interface waviness and volume fraction of the melt zones increase, the resistivity increases substantially. The experimental data demonstrate that the bonding between both metals is always achieved by surface melting of several tenths of a nanometer, which can be detected only by transmission electron microscopy. Most of the phases that form within the melt zones do not appear in the equilibrium phase diagram and show an amorphous/nano-grained structure. Only a very small amount of equilibrium phases such as $\mathrm{CuTi}_{3}, \mathrm{Cu}_{3} \mathrm{Ti}_{2}, \mathrm{Cu}_{4} \mathrm{Ti}_{3}$ was revealed employing synchrotron X-ray diffraction.
\end{abstract}

https://doi.org/10.1007/s11661-019-05537-x

(C) The Author(s) 2019

\section{INTRODUCTION}

LAYERED composites with built-in functionalities are attractive materials for many industrial applications because they offer an optimum balance between manufacturing and service costs, and the durability to perform under their conditions of use. For example, bi- and multi-layer materials composed of reactive metals are used in power, ${ }^{[1]}$ chemical, ${ }^{[2,3]}$ and shipbuilding $^{[4-7]}$ industries, where corrosive wear of equipment is a significant problem. Many material issues related to the use of hydrogen as a fuel can also be solved by the use of layer composites based on reactive metals. ${ }^{[8]}$ For clads used in electro-technical applications, the proper combination of low resistivity and high strength is needed. Copper-titanium $(\mathrm{Cu} / \mathrm{Ti})$ composites are one of

HENRYK PAUL, WOJCIECH SKUZA, ROBERT CHULIST, MAGDALENA MISZCZYK, and JANUSZ PSTRUŚ are with the Institute of Metallurgy and Materials Science PAS, 25 Reymonta St., 30-059 Kraków, Poland. Contact e-mail: h.paul@imim.pl ALEKSANDER GAŁKA is with the ZTW Explomet, 100H Oświęcimska St., 45-641 Opole, Poland. MARIUSZ PRAŻMOWSKI is with the Opole University of Technology, Faculty of Mechanics, 5 Mikołajczyka St., 45-271 Opole, Poland.

Manuscript submitted February 19, 2019.

Article published online November 11, 2019 the industrially relevant two-layered materials used in this field. Since $\mathrm{Cu} / \mathrm{Ti}$ has excellent conductivity (even in corrosive environments), it is widely used as busbars to supply current in galvanizing lines or as anodes in various electrolysis processes. ${ }^{[9,10]} \mathrm{A}$ variety of methods have been used for the effective joining of $\mathrm{Cu}$ and $\mathrm{Ti}^{[11-18]}$ However, only explosive welding (EXW) has the potential to produce large, full-sized plated coatings of varying thickness ${ }^{[19]}$ at a reasonable price.

EXW is a solid-state processing technique that uses controlled explosive energy to bond two or more dissimilar metals. However, due to its sudden and rapid reaction, it is difficult to predict the structural transformations occurring near the interface and their impact on clad properties. For EXW sheets, the process is based on their collision at high velocities caused by the controlled detonation of an explosive charge. ${ }^{[20,21]}$ The distance between the sheets allows acceleration of the flyer plate, the flyer plate bending, and oblique collision with the base plate (Figure 1). The flyer plate movement initiates the formation of a jet of heated gases that removes oxides from the joint area. The oblique collision combined with fast heating and local melting under very high pressure followed by rapid cooling leads to extensive microstructure changes in the areas near the EXW plate joints. Such conditions lead to interface 
(a)

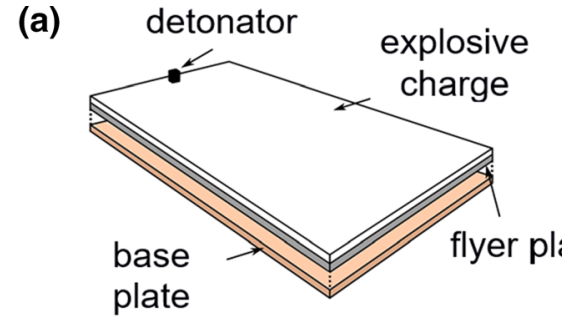

(b)

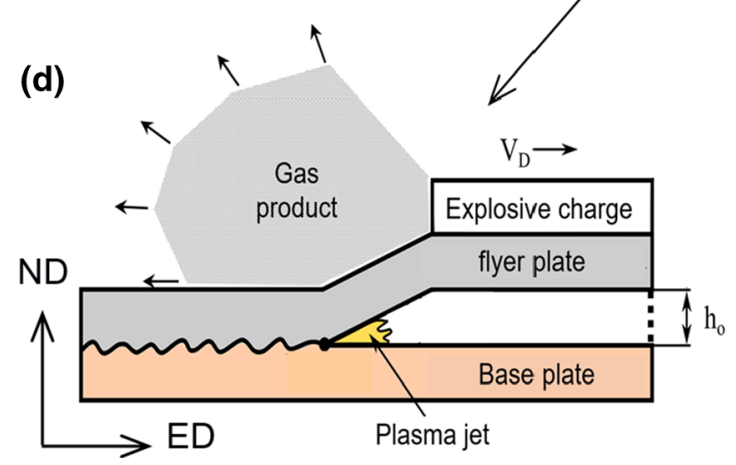

(c)

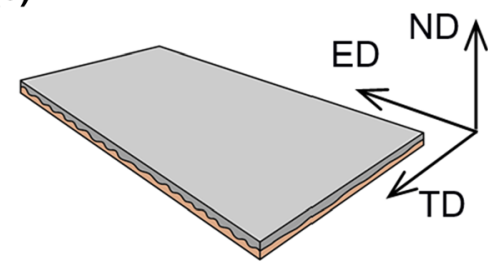

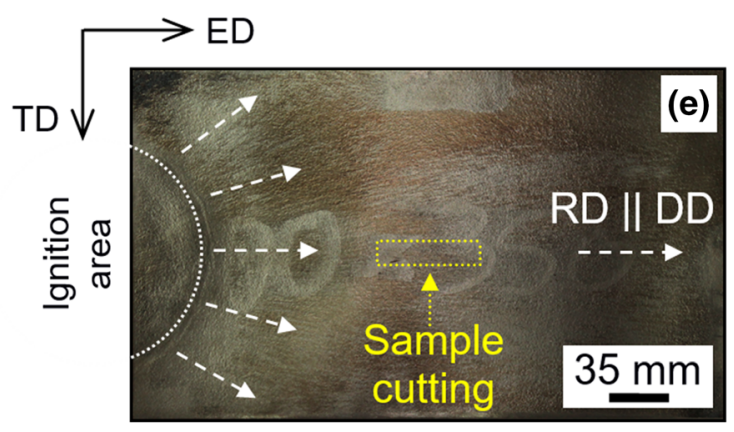

Fig. 1-Schematic sketch of the EXW process: $(a)$ Initial setup showing the parallel geometry of the plates, $(b)$ EXW in progress - bending of the flyer plate, $(c)$ joined plates. $(d)$ Changes near the collision point/line. (e) Final Ti/Cu clad with marked ignition area $\left(V_{D}-\mathrm{detonation}\right.$ velocity, $h_{o}$-stand-off distance). The sample for microstructural and mechanical analysis cut from the place marked in yellow. RD and DD - rolling and detonation directions, respectively (Color figure online).

waviness and determine the strength of the clad. Also, the very short heat impulse times and good thermal conductivity of metals provoke very high cooling rates. ${ }^{[22]}$ Therefore, during solidification, the melt metals exhibit a strong tendency to form brittle crystalline, ${ }^{[23]}$ quasi-crystalline, ${ }^{[22]}$ nano-grained, or amorphous phases. ${ }^{[2,24-26]}$ Simultaneously, the interfacial layers of bonded metals undergo severe plastic deformation forming nano-grained structures. ${ }^{[22-27]}$ It was found that wavy interfaces with a limited quantity of melt zones produce better mechanical properties in contrast to flat melt bonds. ${ }^{[20]}$ However, too much waviness ${ }^{[28,29]}$ and too many melt zones which form a semi-continuous interlayer can exert a detrimental effect on the performance of the bimetal.

The experimental data, which link the bonding parameters to the interface waviness in various cladding systems, have been presented in earlier works. These efforts, reviewed by Mendes et al. ${ }^{[30]}$ discuss the number of explosive charges, ${ }^{[19]}$ collision angles, ${ }^{[31,32]}$ thickness ratios between the flyer and base plates, ${ }^{[33,34]}$ and loss of kinetic energy. ${ }^{[21,35]}$ However, questions still remain regarding the explosive welding process, viz., the precise calculation of the boundaries of the so-called bonding window, ${ }^{[20]}$ the effect of the liquid phase on bond formation, the cause of softening in strain-hardened layers of the parent plates, ${ }^{[23,24,36]}$ and the evolution of the phase structure in the solidified melt zones during heating. ${ }^{[27,37]}$ The mechanism of wave formation at the interface of the EXW plates and sheets remains another poorly understood topic. ${ }^{[36]}$ The increase of waviness with stand-off distance on $\mathrm{Cu}$ and stainless steel clads was reported by Durgutlu et al. ${ }^{[38]}$ and on $\mathrm{Ti}$ and stainless steel clads by Kahraman et al. ${ }^{[39]}$ but without a quantitative description of these effects. The main finding was that increasing the stand-off distance between plates changed the bonding interface from a relatively smooth to a wavy shape. A similar correlation between detonation velocity and interface waviness was found by Mousavi and Sartanagi ${ }^{[40]}$ in $c p$-Ti/ASI 304 stainless steel. Kahraman and Gulenc showed a direct correlation between the amount of explosive material and the interface waviness for $\mathrm{Ti} / \mathrm{Cu}$ clads. ${ }^{[19]}$ The amount of explosive material influences the loss of energy during the explosion, which in turn is proportional to the impact velocity and mass per unit area of the colliding plate. ${ }^{[41]}$ The latter aspect was also analyzed by Manikandan et al. ${ }^{[35]}$ who showed a direct correlation between waviness and the loss of kinetic energy in Ti/stainless steel clads.

However, to the best of the authors' knowledge, no reports have been published on the relationship between EXW parameters and electrical resistivity. This issue becomes challenging to analyze due to the factors that influence electrical resistivity. Nevertheless, some guidelines can be proposed by investigating the type of bonding interface produced as the stand-off distance and detonation velocities are varied while maintaining the necessary mechanical properties. The question then becomes whether these clads will still show the desired electrical conductivity. Despite extensive research efforts over the past several years, only a few publications have investigated the $\mathrm{Cu}-\mathrm{Ti}$ explosive cladding interface. Among these studies, those based on detailed transmission electron microscopy (TEM) analyses are scarce ${ }^{[42,43]}$ Therefore, the purpose of the present work is to define the effect of detonation velocity and stand-off distance on the microstructural changes close to the interface and then correlate these changes with electro-mechanical properties of the clad. The analysis 
was done using TEM and scanning electron microscopy (SEM), high-energy synchrotron radiation tests, mechanical testing, and electrical resistivity measurements. The welding conditions were chosen through parallel geometry with various stand-off distances and intensity of explosive loads.

\section{EXPERIMENTAL}

\section{A. Materials and the Explosive Welding Process}

To produce $\mathrm{Cu} / \mathrm{Ti}$ clads, deoxidized high phosphorus (DHP) $\mathrm{Cu}$ and $\mathrm{Ti}$ (Gr.1) were used as the base plate and the flyer plate, respectively. The initial state of the plates was characterized as a uniform, fully recrystallized microstructure. Both sections perpendicular to the rolling plane showed nearly equiaxed grains (Figure 2). The average grain size was determined to be $\sim 85 \mu \mathrm{m}$ for $\mathrm{Ti}$ and $\sim 55 \mu \mathrm{m}$ for $\mathrm{Cu}$. The EXW process was performed by High Energy Technologies Works 'Explomet' (Opole, Poland). A parallel arrangement of the plates with dimensions of $200 \mathrm{~mm}$ (width) $\times 350 \mathrm{~mm}$ (length) $\times 3 \mathrm{~mm}$ (thickness) was used for clad manufacturing. The stand-off distance $\left(h_{o}\right)$ between the plates was set between 1.5 and $9.0 \mathrm{~mm}$ at $1.5 \mathrm{~mm}$ intervals. The contact surfaces of the joined plates were ground, cleaned of solid particles, and degreased. An explosive charge from Ammonium Nitrate Fuel Oil (ANFO) group was placed on the flyer plate with a detonator located in the middle of its shorter edge. For this configuration, the rolling direction (RD) was aligned parallel to the explosive welding direction (ED) in the middle section of the sheets (Figure 1(e)). The welding process was carried out with explosive charges having different quantities of sensitizing agents that led to different detonation velocities, $V_{D}$ (2000, 2500, and $3000 \mathrm{~m} \mathrm{~s}^{-1}$ ). However, the mass of the explosive charge was the same for each sample. The detonation velocity was measured using an Explomet-Fo-2000 (Kontinitro). This device is described in detail by Tete et al. ${ }^{[4]}$

\section{B. Microstructure and Phase Analyses}

Samples for microscopic observation and mechanical testing were cut from the central region of the clad, with the RD aligned parallel to the direction of the propagation of the explosion wave (Figure 1). These samples were prepared by grinding with abrasive papers and then polishing with diamond pastes. The final step in the preparation procedure was polishing using a vibratory polisher (Buehler, Vibromet 2). Analysis of the interface morphology was carried out employing high-resolution SEM (FEI Quanta 3D), equipped with a field emission gun (FEG) and an energy-dispersive X-ray spectrometer (EDX). The parameters describing waviness of the interface and the total area of the melt zones were determined in the ND/ED (where ND is normal direction) plane with the use of a backscattered electron (BSE) detector in the SEM and ImageJ software. Measurements were performed on 10-mm-long samples. For each case, the average wave height, average wavelength, melt depth equivalent factor (RGP), and the ratio of the length of the interface between the melt zone and parent metals to total length of the interface were calculated (BLF factor). The RGP factor was derived from the following formula, $R G P=S / L$, where $S$ is the sum of the melt zone areas and $L$ is the length of the joint line. The BLF factor was calculated using this formula, $B L F=B / L$, where $B$ is the sum of the length of the interface between the zones of solidified melt and parent metals. ${ }^{[45]}$

SEM analyses were supplemented by TEM observations. The thin foils were obtained from the central parts of the clad. They were cut perpendicularly to the transverse direction (TD) of the bonded sheets using an FEI Quanta 3D 200 Focused Ion Beam system. Thus, the ND and ED directions were parallel to the thin foil edges. The microstructure observations were carried out using an FEI Technai Super TWIN G2 FEG $(200 \mathrm{kV})$ microscope equipped with an EDAX energy-dispersive X-ray (EDX) microanalysis system. Phase analysis near the interfaces was performed using
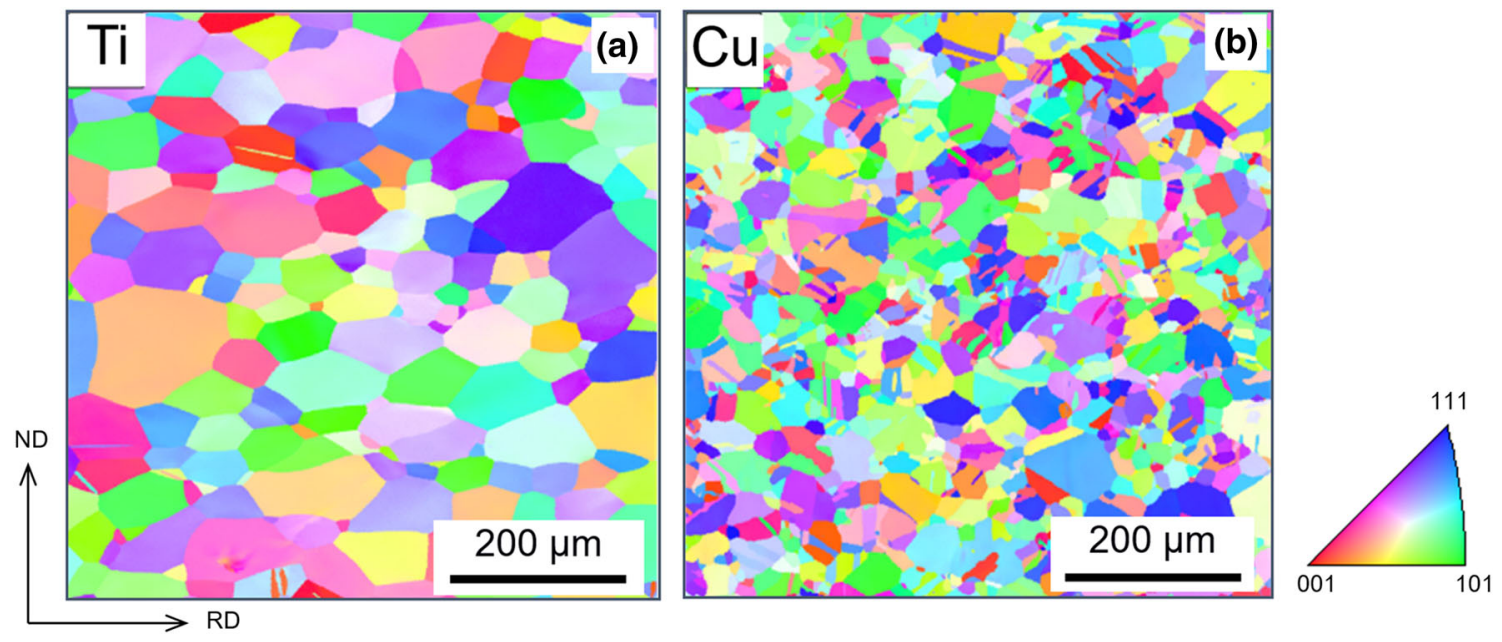

Fig. 2-The initial microstructure of plates observed in the ND/RD section: (a) Ti(Gr1) and (b) $\mathrm{Cu}(99.98)$. SEM/EBSD (EBSD: electron backscattered diffraction) local orientation measurements with a step size of $500 \mathrm{~nm}$. 
high-resolution X-ray diffraction (XRD) spectroscopy with synchrotron radiation using an HZG beamline (P07B) located at PETRA III (electro storage ring operating at energy $6 \mathrm{GeV}$ with a beam current of 100 $\mathrm{mA}$ ) at DESY, Hamburg, Germany. For more details on the measurement procedure, see Reference 46.

\section{Mechanical Testing and Electrical Resistance Measurements}

Microhardness measurements, tensile-shear, and Charpy tests were performed to characterize the mechanical properties of the clad. All samples were cut from the central part of the clads, as shown in Figure 1(e). Vickers microhardness measurements were performed on the polished longitudinal sections with the use of a LECO MHT Series 200 microhardness tester and a load of $50 \mathrm{G}$ (or $100 \mathrm{G}$ inside the melt zones) and a dwell time of 15 seconds. Tensile-shear tests were performed according to the ASTM D 3165-95 standard. Specimens with a size of $50 \times 10 \times 6 \mathrm{~mm}^{3}$ (Figure 3(a)) were cut from the joined sheets with the shear (tensile) direction parallel to the detonation direction. Five samples were tested for each bonding parameter. The results of tensile-shear tests are presented in diagrams showing the change in tensile strength $\left(R_{m}=F_{m} / A_{o}\right.$, where $F_{m}$ is the maximal force, $A_{o}$ is the initial cross-section area) as a function of the stand-off distance for a given detonation velocity. Charpy tests were performed on specimens without a v-notch by using the Charpy hammer. Samples with a size of $55 \times 10 \times 6 \mathrm{~mm}^{3}$ were cut along the ED from the clads with the lowest and the highest quantity of solidified melt zones. The samples were then impact-tested on both the $\mathrm{Ti}$ and $\mathrm{Cu}$ sides. Both sample geometries, i.e., for the tensile-shear and the Charpy tests, are presented in Figure 3(b).

Electrical resistivity measurements were collected at room temperature on non-annealed samples, i.e., just after EXW. In this case, the approach used was a traditional four-point contact method. This method eliminates the effects of contact resistance between the sample and electrical contacts. Finally, using the formula $\left.\quad \rho_{\text {relative }}=\rho_{\text {clad }} / \times \rho_{\mathrm{Ti}}+\mathrm{Cu}_{(\text {vol fraction })} \times \rho_{\mathrm{Cu}}\right)$.
$\left(\mathrm{Ti}_{(\text {vol fraction })} \times \rho_{\mathrm{Ti}}+\mathrm{Cu}_{(\text {vol fraction })} \times \rho_{\mathrm{Cu}}\right)$, the relative resistivity of the clad was calculated, where $\mathrm{Ti}_{\text {(vol. fraction) }}$ and $\mathrm{Cu}_{\text {(vol fraction) }}$ are the volume fractions of the Ti and $\mathrm{Cu}$ layers in the clad, respectively, and $\rho$ is the electrical resistivity. The standard deviation was estimated using ten measurements on each sample. A coverage factor of two was applied to get an interval with 95 pet confidence. A similar procedure was applied in Reference 47 for resistivity evaluation of the copper-clad-aluminum composites prepared using a restacking drawing method.

\section{RESULTS}

\section{A. Wave Morphology: Interface Overview}

SEM examination of the $\mathrm{Ti} / \mathrm{Cu}$ joints confirmed their quality. No fractures nor discontinuities were observed in the parent materials near the interfaces. Some cracks inside the melt zones appeared accidentally. The interfaces showed a characteristic sharp transition indicating that there was no mechanical mixing between the welded metals in the solid state. The effect of stand-off distance and detonation velocity on the structural changes at the weld interfaces are illustrated in Figure 4, and the geometrical parameters describing the waves (period and amplitude) are summarized in Figures 5(a) and (b).

The interfaces for all tested samples showed a wavy character. The wave amplitude and wave period increased with increasing detonation velocity and stand-of distance. This observation is consistent with the work reported by Livne and Munitz ${ }^{[48]}$ on $\mathrm{Fe}$ and $\mathrm{Cu}$ plates, Durgutlu et al ${ }^{[38]}$ on $\mathrm{Cu}$-stainless steel clads, and Kahraman et al. ${ }^{[39]}$ on Ti-stainless steel clads. These works showed that increasing stand-off distance between both plates changes the bonding interface from a relatively smooth to a wavy shape. A similar correlation between detonation velocity and interface waviness was found by Mousavi and Sartanagi ${ }^{[40]}$ in $c p$-Ti/ASI 304 stainless steel clads.

However, our experimental data provide a more systematic analysis. Our results show that for a detonation velocity of $2500 \mathrm{~m} \mathrm{~s}^{-1}$, the average amplitude increases from 23.9 to $261.3 \mathrm{~mm}$, whereas the average

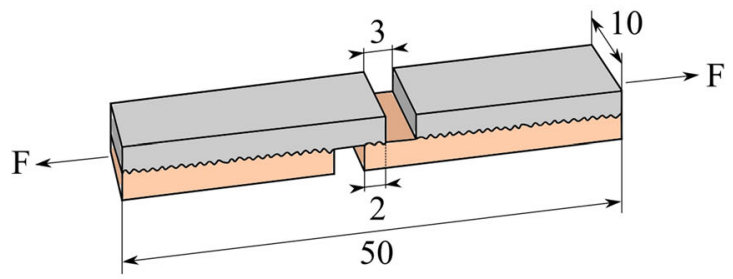

(a)

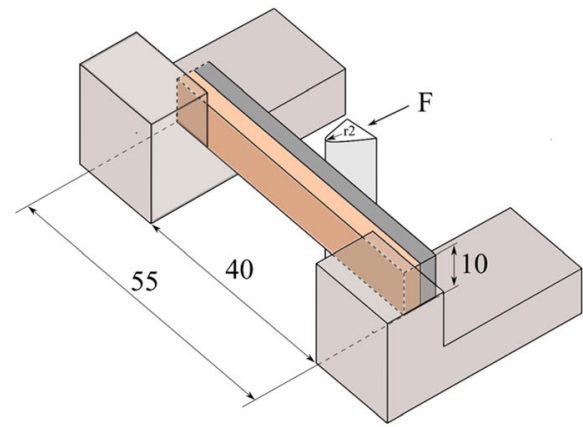

(b)

Fig. 3-The sample dimensions for $(a)$ shear and (b) Charpy tests. Ti and $\mathrm{Cu}$ plates are marked in gray and brown, respectively (dimensions in $\mathrm{mm})$. 


\section{Detonation velocity}

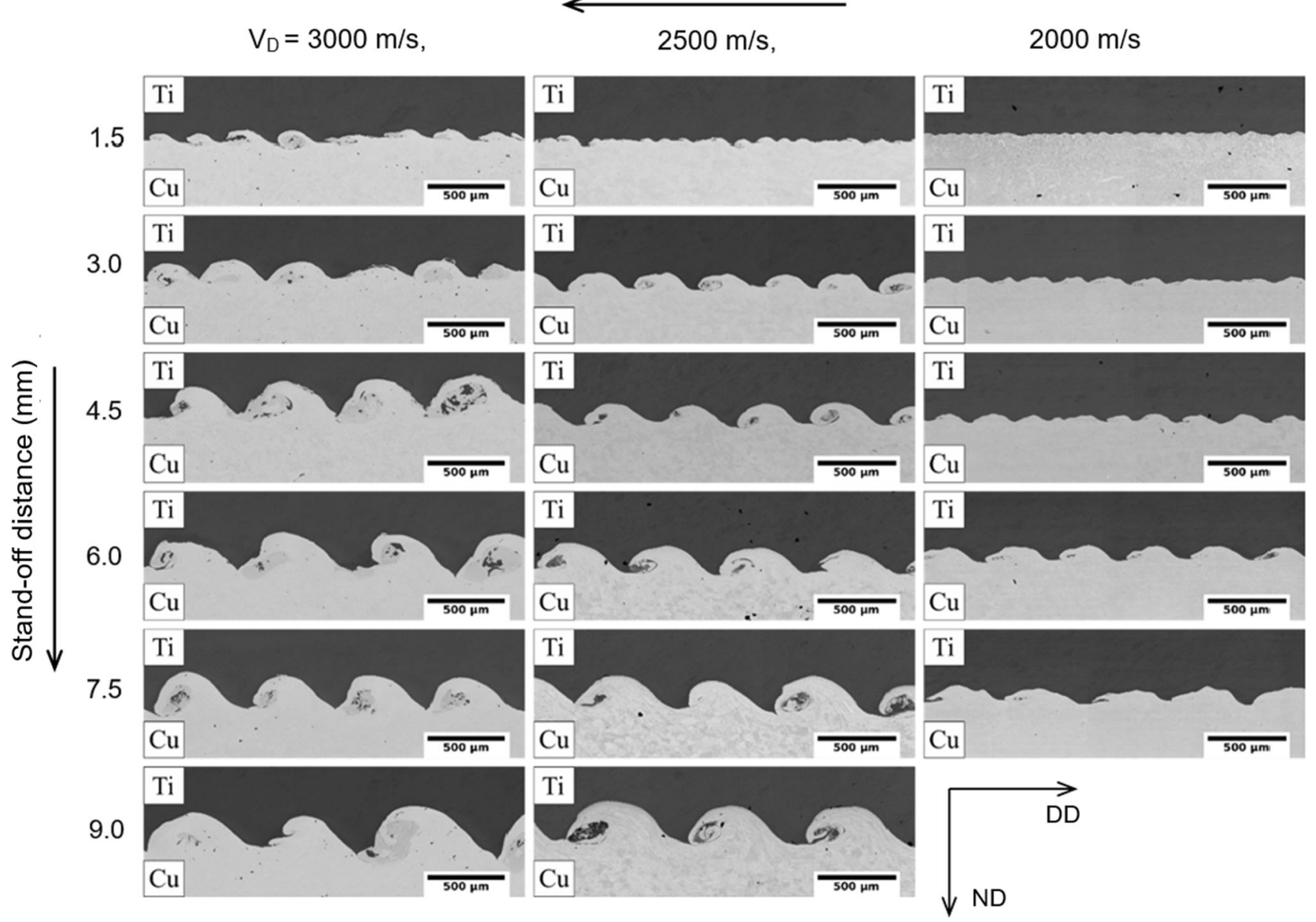

Fig. 4-SEM/BSE imaging in the ND/ED section showing the impact of stand-off distance and detonation velocity on wave formation near the interface.

wave period (length) increases from 128.0 to $738.4 \mathrm{~mm}$ at stand-off distances of 1.5 and $9.0 \mathrm{~mm}$, respectively. For the $1.5 \mathrm{~mm}$ stand-off distance, the wave amplitude increases from 13.2 and $91.4 \mathrm{~mm}$ up to 65.9 and 267.0 $\mathrm{mm}$ for detonation velocity of 2000 and $3000 \mathrm{~m} \mathrm{~s}^{-1}$, respectively. For a detonation velocity of $3000 \mathrm{~mm} \mathrm{~s}^{-1}$, the wave parameters significantly increased for stand-off distances lower than $6.0 \mathrm{~mm}$. Larger values did not significantly affect the amplitude and period of the wave. An interesting observation was made for the stand-off distance of $9 \mathrm{~mm}$, where the wave amplitude and length were lower at $3000 \mathrm{~m} \mathrm{~s}^{-1}$, (amplitude $=239 \mu \mathrm{m}$, length $=627 \mu \mathrm{m})$ than for $2500 \mathrm{~m} \mathrm{~s}^{-1}, \quad(261 \mu \mathrm{m}$, $738 \mu \mathrm{m})$.

The wave formation coincides with the occurrence of solidified melt zones, which were observed (with various intensity) in all clads. The large zones of solidified melt were preferentially located near the front slope of the waves or within the vortexes of the waves. As expected, the RGP factor increased as the detonation velocity increased, but for some detonation velocities not always in a monotonic way. The highest RGP value of $18.2 \mu \mathrm{m}^{2} \mu \mathrm{m}^{-1}$ was obtained for a stand-off distance of $9.0 \mathrm{~mm}$ and detonation velocity of $3000 \mathrm{~m} \mathrm{~s}^{-1}$, whereas the lowest of $0.11 \mu \mathrm{m}^{2} \mu \mathrm{m}^{-1}$ for $1.5 \mathrm{~mm}$ and $2000 \mathrm{~m} \mathrm{~s}^{-1}$ (Figure 5(c)).

\section{B. Large Melt Zone Formation}

The solidified melt zones were preferentially formed within wave vortexes and to a lesser degree at the wave crest or as inclusions inside the $\mathrm{Cu}$ plate. This general observation is typical and was found for other explosively welded metal compositions. ${ }^{[23-26,37,49]}$ The internal microstructure of the solidified melt zones is composed of a mixture of the amorphous areas, small equiaxed grains (the diameter of these grains ranged from 0.1 to $1.0 \mu \mathrm{m}$ ), and small columnar grains (Figure 5). The majority of grains resemble small dendrites with clearly developed cores and arms. In some cases, the complex force interaction during clad formation locally pushed the solid material into the liquid or semi-liquid material. As a result, the parent material $(\mathrm{Cu}$ or $\mathrm{Ti})$ occasionally was enclosed inside the solidified melt (Figure 6).

Two types of large solidified melt zones were observed inside the wave vortexes. The first is situated inside the vortex, formed in the $\mathrm{Cu}$ plate, but still partly adjacent to $\mathrm{Ti}$. The other is entirely surrounded by $\mathrm{Cu}$, without 


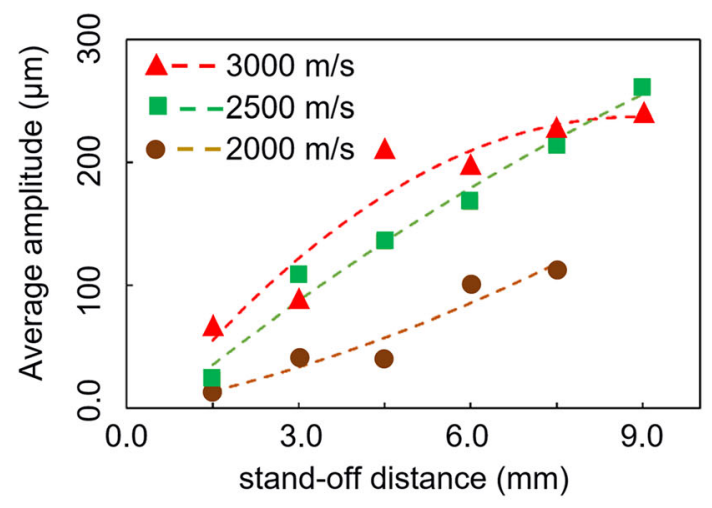

(a)

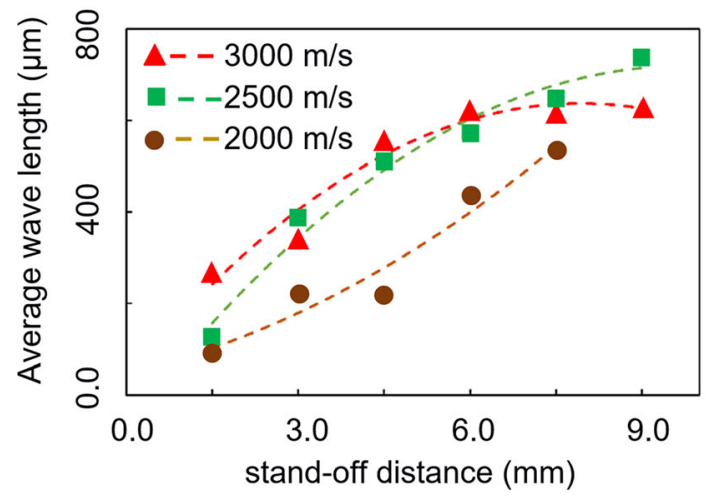

(b)

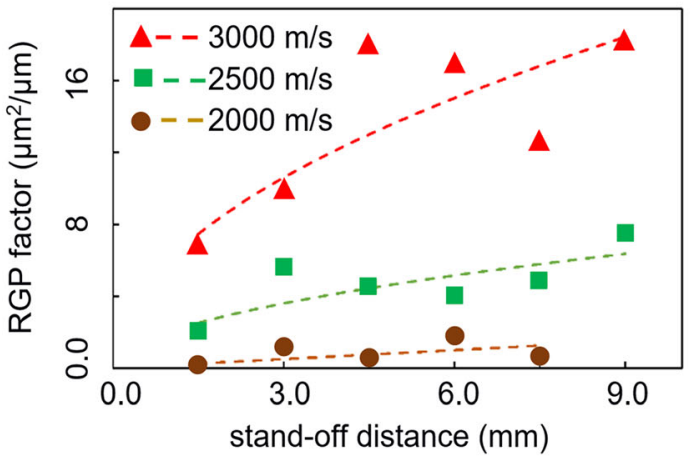

(c)

Fig. 5-The influence of stand-off distance and detonation velocity on $(a)$ amplitude, $(b)$ period of the waves, and $(c)$ quantity of melt zones described by the RGP factor.

any contact with $\mathrm{Ti}$ (at least in the section analyzed). The most characteristic feature for the first type is the occurrence on the wave crest of a "drag effect" of molten or semi-molten material (Figures 7(a) and (b)). This leads to the formation of a thin layer of the solidified melt between $\mathrm{Ti}$ and $\mathrm{Cu}$ on the wave crests. A circular material displacement is observed not only on the wave crest but also in the vortexes, where intense stirring leads to a non-homogeneous distribution of elements within the melt zone (Figures 7(c) through (f)). Figure 7 shows another type of melt zone, where the solidified melt is fully enclosed within the wave vortex. Different contrasts are shown in the SEM/BSE images in Figures 8(a) and (b), and the element distribution on the SEM/EDX maps (Figures 8(c) and (d)), which confirm intense stirring in the liquid and semi-liquid state(s). The point (Table I) and line (Figure 8(e)) chemical composition analyses took across the melt zone for the clad prepared at the highest bonding parameters, i.e. $3000 \mathrm{~m} \mathrm{~s}^{-1}$ and $9 \mathrm{~mm}$ (highest RGP value of $18.2 \mu \mathrm{m}^{2} \mu \mathrm{m}^{-1}$ ) reveal different phases with various chemical compositions. Although most of them do not appear in the $\mathrm{Cu}-\mathrm{Ti}$ phase diagram, they are distinguishable and correspond to some equilibrium phases, like $\mathrm{Cu}_{4} \mathrm{Ti}, \mathrm{Cu}_{2} \mathrm{Ti}, \mathrm{CuTi}$, or $\mathrm{CuTi}_{2}$ (Figure 8(e)).

The internal microstructure and chemical composition of the melt zones formed at lower bonding parameters are similar to the highest ones, despite the difference in wave morphology, size, and shape of the melt zones and the intensity of their formation. SEM/ EDX point and line scans show that besides the four phases observed in Figure 8, some areas correspond to the $\mathrm{Cu}_{3} \mathrm{Ti}_{2}$ and $\mathrm{Cu}_{4} \mathrm{Ti}_{3}$ equilibrium phases. For all detonation velocities and stand-off distances, the areas of different chemical composition are randomly distributed within the solidified melt zones, but in some places, they reveal a specific swirl-like distribution of elements.

Diffraction experiments in transmission geometry using synchrotron radiation were performed to identify intermetallic phases occurring in the melt zones. Although the conditions during EXW are far from equilibrium, at a first approximation, the obtained results were referred to those observed in equilibrium phase diagrams. Figure 9 shows a diffraction pattern from the clad intermediate layer containing the largest quantity of solidified melt zones (RGP equals $18.2 \mu \mathrm{m}^{2} \mu \mathrm{m}^{-1}$. The diagram reveals reflections from $\mathrm{Ti}$ and $\mathrm{Cu}$. However, a closer look shows reflections from phases based on compounds in the two-component equilibrium phase diagram $\left(\mathrm{CuTi}_{3}, \mathrm{Cu}_{3} \mathrm{Ti}\right.$, and $\mathrm{Cu}_{4} \mathrm{Ti}_{3}$; see inset in Figure 8). Employing the Rietveld refinement, a very small amount of intermetallic phases with a volume fraction ranging between 0.2 and 0.5 pet $(0.5 \times$ $0.5 \times 4 \mathrm{~mm}^{3}$ ) was calculated. Such a low volume fraction of intermetallic phases is quite surprising and suggests that most of the area investigated by EDX is a mixture of pure $\mathrm{Ti}$ and $\mathrm{Cu}$.

\section{Thin Melt Zone Formation}

Figure 7(b) shows that a thin layer is formed as a result of the drag effect of molten or semi-molten material within the melt zones. However, a thin reaction layer can also be built on the flat parts of the interface, without any direct contact with the large melt zones. These findings are consistent with the hydrodynamic approach for EXW, which assumes that under specific modes of the impact, the material behaves like a fluid. ${ }^{[40,50]}$

These areas are indicated by white arrows in Figure 10(a). Such a thin layer can be overlooked with optical microscopy or even low-magnification SEM. However, using TEM, the presence of a continuous layer with a thickness ranging from 50 to $200 \mathrm{~nm}$ is indisputably proved (Figure 10(b)). This layer is 


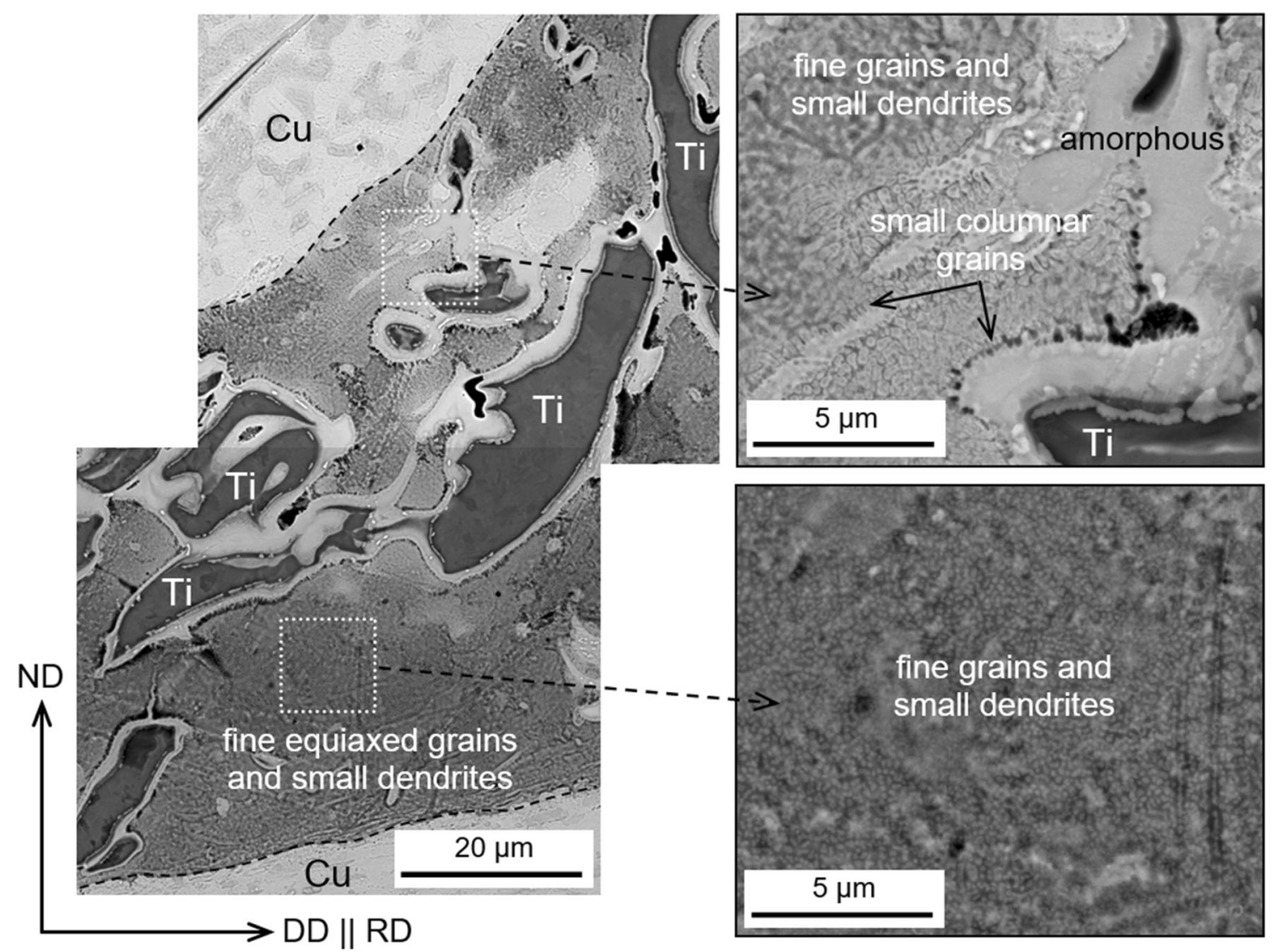

Fig. 6-The internal structure of a large solidified melt zone inside the wave vortex. SEM/BSE (where: BSE: backscattered electrons) images showing the coexistence of the structural elements of different morphologies, i.e., amorphous areas, fine equiaxed and columnar grains, small dendrites, and fragments of Ti plate closed inside the melt zone. EXW welding at detonation velocity of $3000 \mathrm{~m} \mathrm{~s}^{-1}$ and stand-off distance of $9 \mathrm{~mm}\left(\mathrm{RGP}=18.2 \mu \mathrm{m}^{2} \mu \mathrm{m}^{-1}\right)$.

composed of a solidified liquid and/or nanograins (Figures 11(a) through (c)). The TEM/EDX chemical composition maps show a small variation of both main element distributions in the melt zone. The only trend is increasing $\mathrm{Cu}$ or $\mathrm{Ti}$ content near the parent plates (Figures 11(d) and (e)). These subtle chemical composition changes are more evident in Figure 12(a), where across the solidified melt layer TEM/EDX line scan marked in Figure 11(a) by dotted arrows) an increased content of $\mathrm{Cu}$ and $\mathrm{Ti}$ near the $\mathrm{Cu}$ and $\mathrm{Ti}$ plates is detected, respectively. The point analyses show that the chemical composition of the solidified melt near the interface between the $\mathrm{Cu}$ and melt layer is given by $\mathrm{Cu}_{0.67} \mathrm{Ti}_{0.33}$, whereas on the other side of the melt layer by $\mathrm{Cu}_{0.46} \mathrm{Ti}_{0.53}$ (see Table II), and in the area between persists a rather stable $\mathrm{Cu}_{(0.45-0.51)} \mathrm{Ti}_{(0.49-0.55)}$ composition (Figure 12(b) and Table II).

\section{Clad Properties}

\section{Mechanical testing}

The results of the tensile-shear tests show that the strength of the interface is higher than that of the copper plate (fracture took place within the copper plate). The shear strength $(R m)$ reaches values between 185 and 205 $\mathrm{MPa}$ (Figure 13) and increases slightly with increasing stand-off distance and detonation velocity. This result can be attributed to strain hardening and grain refinement of the $\mathrm{Cu}$ and Ti sheets in layers near the interface. A similar effect was observed by Kahraman and Gulend ${ }^{[19]}$ on clads without solidified melt zones at the interface. Since the tensile-shear strength of the joint is higher than the strength of $\mathrm{Cu}$, these results satisfy the criteria for a 'good quality joint,' where the strength of the joint is higher than the weaker component (Figures 13(a) and (b)). This means that the applied detonation velocities and stand-off distances allowed to produce good quality $\mathrm{Ti} / \mathrm{Cu}$ clads, and the presence of significantly different quantities of solidified melt zones does not affect the bond strength. A similar tendency was obtained by Livne and Munitz ${ }^{[48]}$ for $\mathrm{Cu} /$ carbon steel clads and by Durgutlu et al ${ }^{[38,51]}$ for $\mathrm{Cu} /$ stainless steel tested according to the same ASTM D 3165-95 standard.

Our next step was dynamic loading on a Charpy hammer using specimens without a v-notch. The samples with the lowest and highest values of the RGP factor $\left(0.11\right.$ and $\left.18.2 \mu \mathrm{m}^{2} \mu \mathrm{m}^{-1}\right)$ were deformed. Using a lateral view, no cracks nor delamination were detected for samples manufactured at a detonation velocity of $2000 \mathrm{~m} \mathrm{~s}^{-1}$ and a stand-off distance of 1.5 (RGP factor equals $0.11 \mathrm{~mm}$ ) (Figure 14(a)), whereas in the sample 


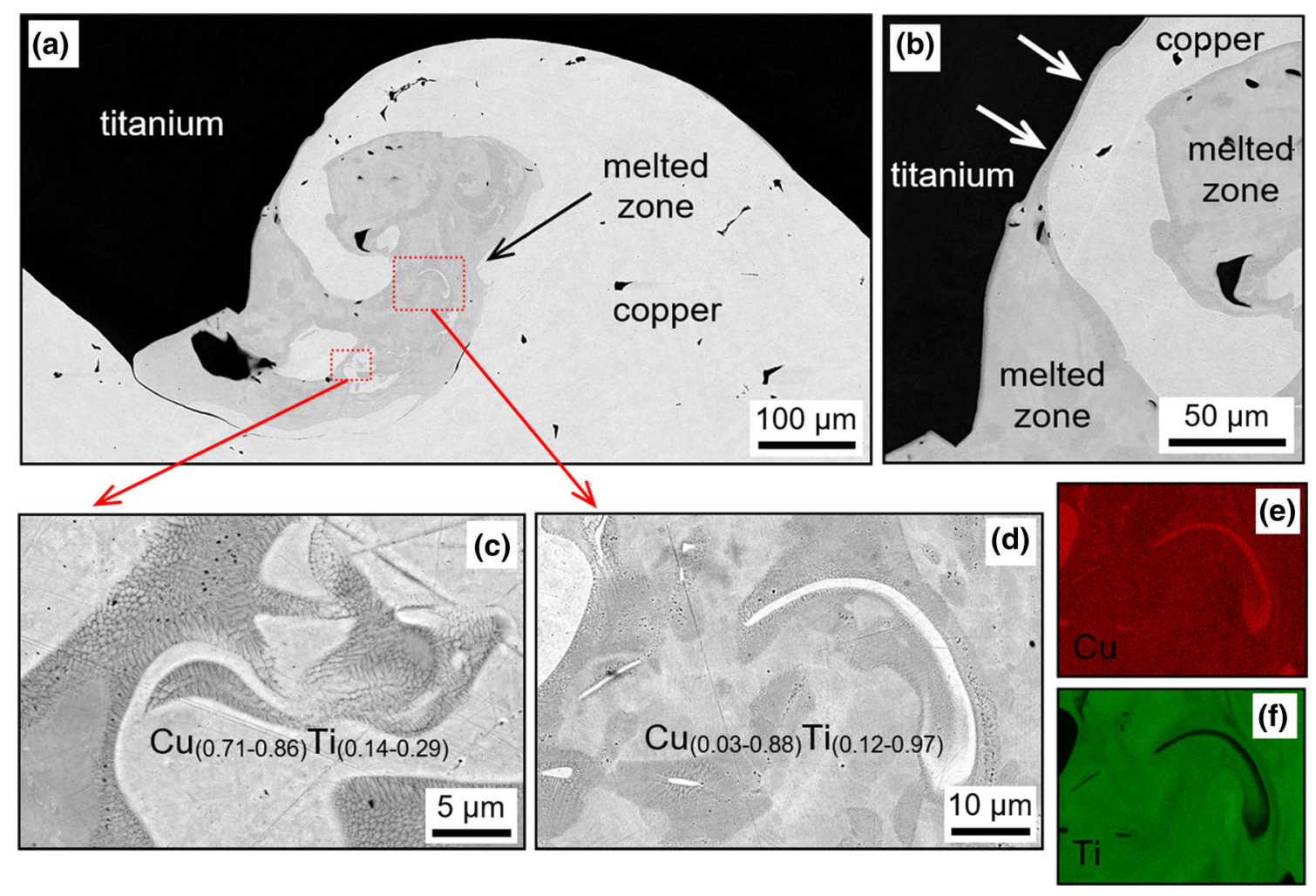

Fig. 7-(a) Large melt zone contacting a Ti plate. (b) A thin layer of a melt zone on the crest of a wave. $(c, d)$ The internal structure of the melt zone and $(e, f)$ rotational character of the chemical element distribution. Explosive welding at a detonation velocity of $3000 \mathrm{~m} \mathrm{~s}{ }^{-1}$ and stand-off distance of $9 \mathrm{~mm}\left(\mathrm{RGP}=18.2 \mu \mathrm{m}^{2} \mu \mathrm{m}^{-1}\right.$ ). SEM/BSE imaging (a through d) and SEM)/EDX chemical composition measurements.

manufactured at $3000 \mathrm{~m} \mathrm{~s}^{-1}$ and $9.0 \mathrm{~mm}$ (RGP factor equals $18.2 \mathrm{~mm}$ ), a small delamination (Figure 14(b)) is observed. However, these small interfacial discontinuities do not show a tendency to propagate towards the parent sheets. The force-displacement characteristics reveal small differences depending on the convex side $(\mathrm{Cu}$ or $\mathrm{Ti})$. The bending displacement was higher, and the value of the maximal force lower if the samples were loaded from the Ti side compared with the $\mathrm{Cu}$ side (Figures 14(c) through (f)). This behavior is directly related to the mechanical properties (under compressive or tensile stresses) of $\mathrm{Cu}$ and $\mathrm{Ti}$.

The distribution of microhardness along the ND in the ND/ED section was recorded (Figures 15(a) and (b)) to show the strain-hardened layers. Three measurements for a given distance from the interface were taken so that the average value could be calculated. Additionally, two qualitatively different regions in areas near the interface were analyzed, i.e., the interface with and without a broad zone in the solidified melt. The microhardness of the initial $\mathrm{Cu}$ and $\mathrm{Ti}$ sheets was $85( \pm 5) \mathrm{HV}_{0.05}$ and $149( \pm 6) \mathrm{HV}_{0.05}$, respectively. Throughout the entire thickness of the sample, the microhardness for the state "after welding" is higher than that in the original materials. In the $\mathrm{Cu}$ layer close to the interface, an increase up to $161 \mathrm{HV}$ is observed, whereas near the free surface $\sim 100 \mathrm{HV}$ is reached. In the $\mathrm{Ti}$ plate, the microhardness values are equal to $\sim 273 \mathrm{HV}$ in the layers near the interface and $200 \mathrm{HV}$ near the explosive charge. The maximum value of microhardness $(273 \mathrm{HV}$ for $\mathrm{Ti}$ and $161 \mathrm{HV}$ for $\mathrm{Cu}$ sheets) was observed near the pure metal-pure metal interface by examining optical microscopy images. Far from the interface, both types of line scans show similar trends.

These results lead to the conclusion that the same stand-off distance with increasing detonation velocity increases the microhardness of joined plates. The increase of microhardness in the layers near the interface can be directly correlated with a substantial strain hardening and grain refinement caused by the highspeed collision of sheets. Consequently, the plastically deformed layer was significantly broader in the Ti plate than in the $\mathrm{Cu}$ plate, where plastic deformation occurs only in the wave regions. One possible explanation is that $\mathrm{Cu}$ is considerably softer than $\mathrm{Ti}$, and the whole plastic deformation accumulates in a smaller volume, i.e., the vortex regions. However, inducing intense recovery and recrystallization can decrease the microhardness in layers situated directly at the large melt zones, since the stored energy is the driving force for recrystallization. ${ }^{[25]}$ This, in turn, leads to material softening. The drop in microhardness in layers of the parent plates near the solidified melt zones was clearly

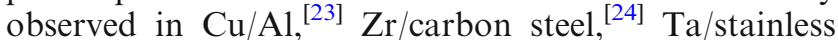
steel, ${ }^{[25]}$ and $\mathrm{Ti} /$ carbon or stainless steel ${ }^{[52]}$ clad. This tendency was correlated with the recovery and recrystallization processes of severely deformed structures. ${ }^{[53]}$ In the case of interfaces without macroscopically visible 

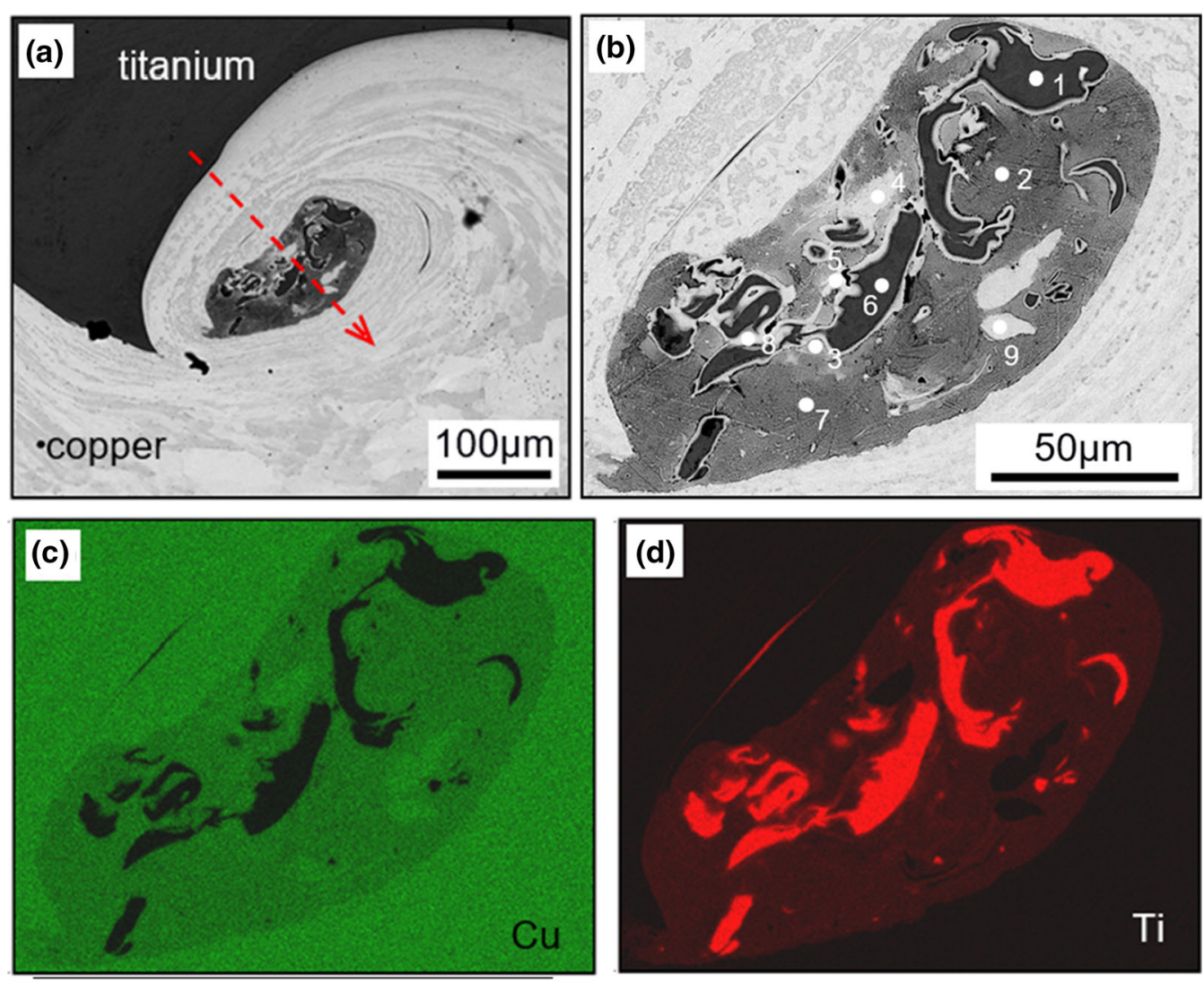

(e)

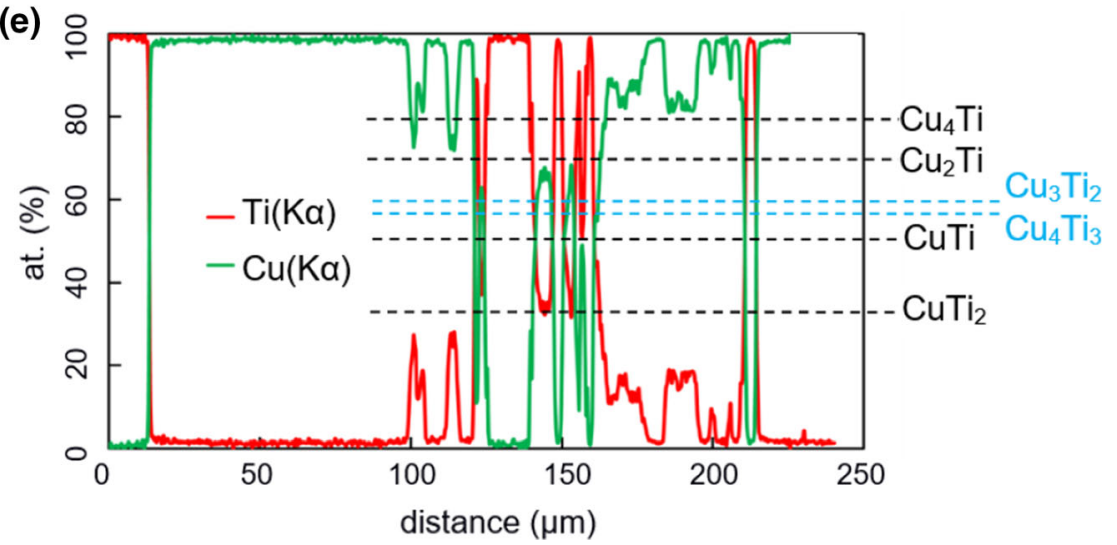

Fig. 8- (a) Large melt zone closed inside the vortex formed in the Cu plate. (b) Internal structure of the melt zone and ( $c$, $d$ ) SEM/EDX maps showing the rotational character of the chemical elements $(\mathrm{Ti}$ and $\mathrm{Cu}$ ) distribution. (e) Chemical composition changes along the line scan marked in (a). The changes are compared with the chemical composition of the phases observed in stable conditions. EXW welding at a detonation velocity of $3000 \mathrm{~m} \mathrm{~s}^{-1}$ and stand-off distance of $9 \mathrm{~mm}\left(R G P=18.2 \mu \mathrm{m}^{2} \mu \mathrm{m}^{-1}\right)$.

melt zones, a continuous increase in the microhardness is always observed.

The microhardness inside the solidified melt inclusions of a large dimension reaches a maximum value of $670 \mathrm{HV}$. This is 2 to 2.5 times higher than those observed in strongly refined (and strain-hardened) layers of $\mathrm{Ti}$ and 4 to 5 times higher than for the $\mathrm{Cu}$ plate. However, a strong scattering of microhardness values ranging between 132 and $670 \mathrm{HV}$ was also observed. The lowest values are connected with the presence of $\mathrm{Cu}$ within the melt zones.

\section{Bonding parameters vs electrical resistivity}

Electrical resistivity measurements were correlated with the microstructure near the interface. Based on measured values of the resistivity of joined metals $\left(\rho_{\mathrm{Ti}}=40 \times 10^{-8}\right.$ and $\left.\rho_{\mathrm{Cu}}=1.8 \times 10^{-8} \Omega \mathrm{m}\right)$, the relative resistivity was estimated for clads manufactured using various EXW parameters. The results are represented in Figure 16(a) and display the relative resistivity of the clads as a function of stand-off distance and detonation velocity. For clads prepared at a given detonation velocity, a near-linear increase in relative 
Table I. SEM)/EDX Point Analysis of Melt Zone (Layer) Showing Chemical Composition

\begin{tabular}{lcc}
\hline & \multicolumn{2}{c}{$\mathrm{V}_{\mathrm{D}}=3000 \mathrm{~m} / \mathrm{s}, h_{\mathrm{o}}=9.0 \mathrm{~mm}$} \\
\cline { 2 - 3 } & \multicolumn{2}{c}{ At. Percent } \\
\cline { 2 - 3 } Point Number & $\mathrm{Ti}(\mathrm{K})$ & $\mathrm{Cu}(\mathrm{K})$ \\
\hline 1 & 96.2 & 3.8 \\
2 & 29.1 & 70.9 \\
3 & 24.3 & 75.7 \\
4 & 15.1 & 84.9 \\
5 & 21.0 & 79.0 \\
6 & 97.4 & 2.6 \\
7 & 42.3 & 57.7 \\
8 & 18.5 & 81.5 \\
9 & 11.9 & 88.1 \\
\hline
\end{tabular}

Results correspond to melt zones presented in Fig. 8(b).

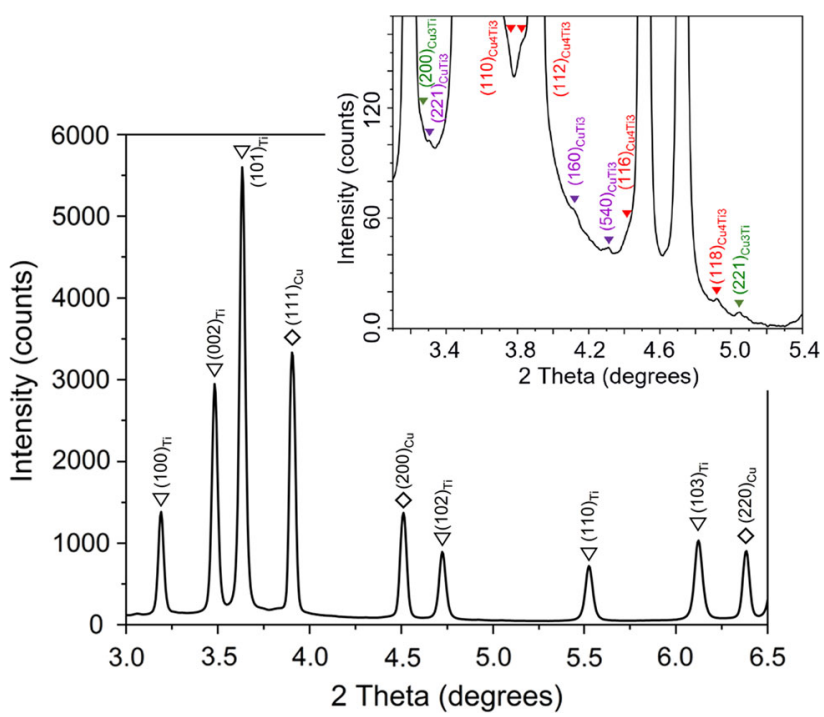

Fig. 9-X-ray synchrotron diffraction pattern for the $\mathrm{Ti} / \mathrm{Cu}$ clad taken from the area, including the interface and both plates $(0.5 \times$ $\left.0.5 \times 10 \mathrm{~mm}^{3}\right)$. Clad manufactures at detonation velocity of $3000 \mathrm{~m} \mathrm{~s}^{-1}$ and a stand-off distance of $9.0 \mathrm{~mm}$.

resistivity with stand-off distance is seen; the higher the detonation velocity, the stronger the increase in relative resistivity. Thus, the RGP (the "quantity" of melt zones) and BLF (the length of interfaces between melt zones and parent metals) parameters describe quite well the structural changes near the interface, showing a linear dependence on the relative resistivity (Figures 16(b) and (c)).

\section{DISCUSSION}

The $\mathrm{Ti} / \mathrm{Cu}$ clads manufactured at stand-off distances from 1.5 to $9.0 \mathrm{~mm}$ and detonation velocities ranging between 2000 and $3000 \mathrm{~m} \mathrm{~s}^{-1}$ fulfill the strength properties necessary for a good quality clad. However, using these bonding parameters, their resistivity varies significantly. In the first approximation, this variation can be related to microstructural changes in the layers near the interface, i.e., formation of (i) waves of different amplitude and period; (ii) melt zones of varying intensity, structures, and chemical compositions; and (iii) severely deformed layers in the parent plates. Some aspects of the above features will be analyzed for their influence on electrical resistivity.

\section{A. Interface Waviness}

The formation of waves at the interface is one of the most essential phenomena accompanying EXW..$^{[20,22,50]}$ However, a complete description of the wave formation process, and in particular, the appearance of the first protrusion, is still difficult to accomplish. Earlier work $^{[19,35,38-41]}$ notes that the interface is quite smooth if a small amount of energy is released in the explosion*,

*The explosive material amount influences the loss of energy during the explosion, which is a function of impact velocity and colliding plate mass, and therefore, influences the waviness of the interface and quantity of melt zones in areas near the interface.

but the wave amplitude and period rise with the amount of released energy. However, our experimental data provide a more systematic analysis concerning the morphology of the interface. The microstructural observations evidence that strong waviness leads to an increase in the area of bonding interface, and it is inherent with a rise in the volume fraction of melt zones. Both factors can be correlated with an increase in the resistivity of the clad. Assuming a stand-off distance equal to zero allows us to extrapolate the relative clad resistivity for this hypothetical situation. The values obtained were $\sim 2.8$ times higher than the average relative resistivity of both materials, independent of the applied detonation velocity. When using these hypothetical conditions, turbulent flow is excluded, and clad formation with a flat interface (amplitude equal to zero) and no melt zones (RPG and BLF coefficients equal to zero) is expected.

However, the relationship between the explosive charge amount and interface waviness is more complicated, as discussed above. The results obtained by Mendes et al. ${ }^{[30]}$ on stainless steel and carbon steel EXW in a cylindrical configuration lead to the conclusion that variation of the wave amplitude and period are more a function of the explosive material type than impact velocity or collision angle.

\section{B. Solidified Melt Zones Formation}

A feature typical for EXW metals is the formation of a liquid phase at the interface. The effect of this phenomenon on the mechanical properties of the clad is ambiguous. On the one hand, an increase in strength is expected due to the formation of intermetallic phases (high hardness). On the other hand, crack formation within the zones of solidified melt has a detrimental effect on the mechanical properties of the clad. The present work documents that the volume fraction of 

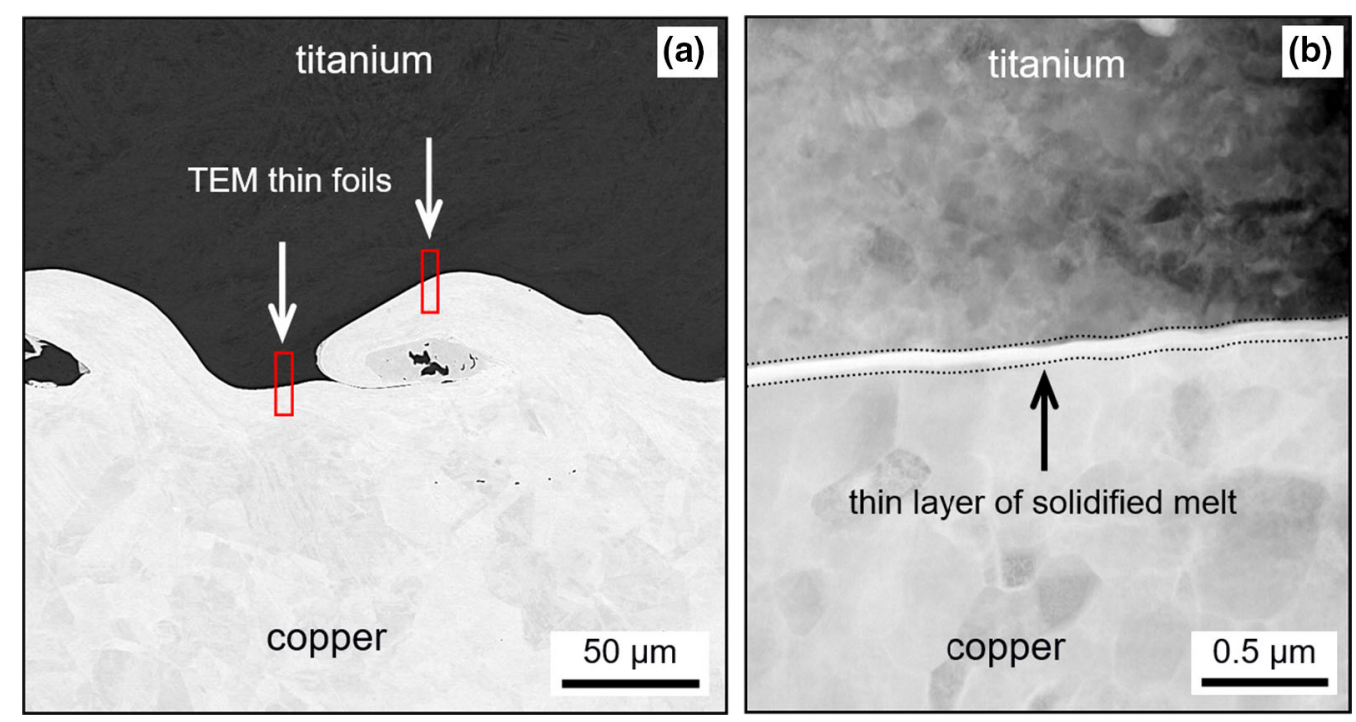

Fig. 10 - (a) Interfacial microstructure observed in SEM scale - white arrows are indicating a part of the interface free of melt zones. SEM/BSE imaging in ND/RD) section. (b) Scanning transmission electron microscopy/high-angle annular dark-field (STEM/HAADF) inspection of thin foils cut from areas indicated by white arrows for (a) a very thin reaction layer. The clad manufactured at a detonation velocity of $2500 \mathrm{~m} \mathrm{~s}$ and stand-off distance of $1.5 \mathrm{~mm}$.
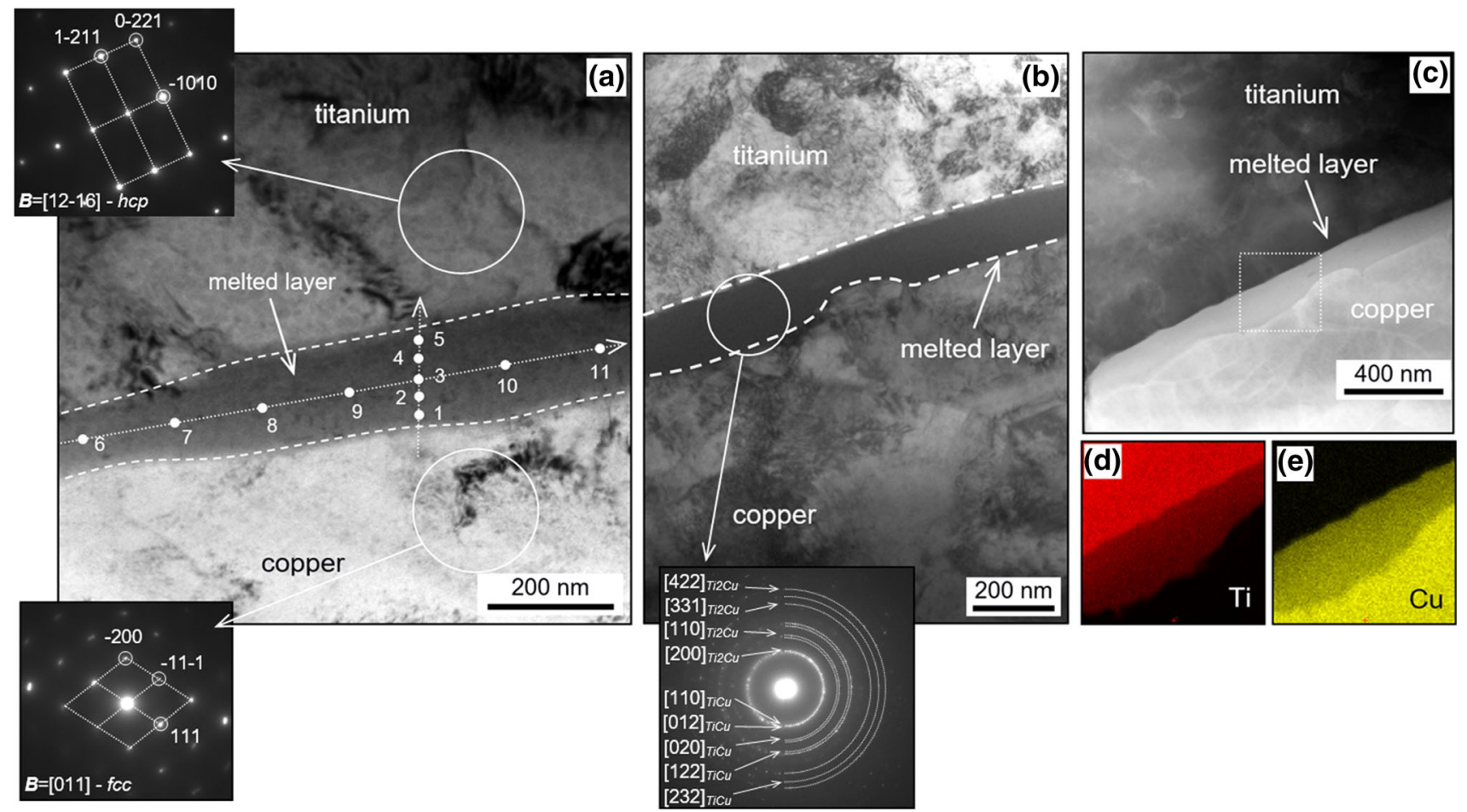

Fig. 11-Microstructure and chemical composition of an extremely thin melt zone formed at the bottom part of the wave $(a)$ and on the crest of the wave $(b)$ through $(e)$. (a, b) TEM bright-field and (c) STEM/HAADF images showing structure of melt zone and joined plates near the interface. (d, e) TEM)/EDX chemical composition maps showing distribution of $\mathrm{Cu}$ and $\mathrm{Ti}$ in the melt zone. Selected area diffraction (SAD) patterns from the parent materials - (a) and melt zone - (b). The clad manufactures at detonation velocity of $2500 \mathrm{~m} \mathrm{~s}^{-1}$ and stand-off distance of $1 \mathrm{~mm}$. The thin foils cut out along the ND/RD section.

large solidified melt zones increases as the detonation velocity and/or stand-off distance increases (see Figure 5(c)). As a consequence, all related features such as fine grain, inhomogeneous distribution of the structure elements, the formation of intermetallic compounds or pores/cracks due to shrinkage of melt zones during solidification cause a reduction of clad conductivity. It was shown that the melt zones were observed on both sides of the wave crest, not only in the form of large zones but also as a thin film along the entire interface. This leads to double interface formation. The present results prove that a proper EXW always incorporates 

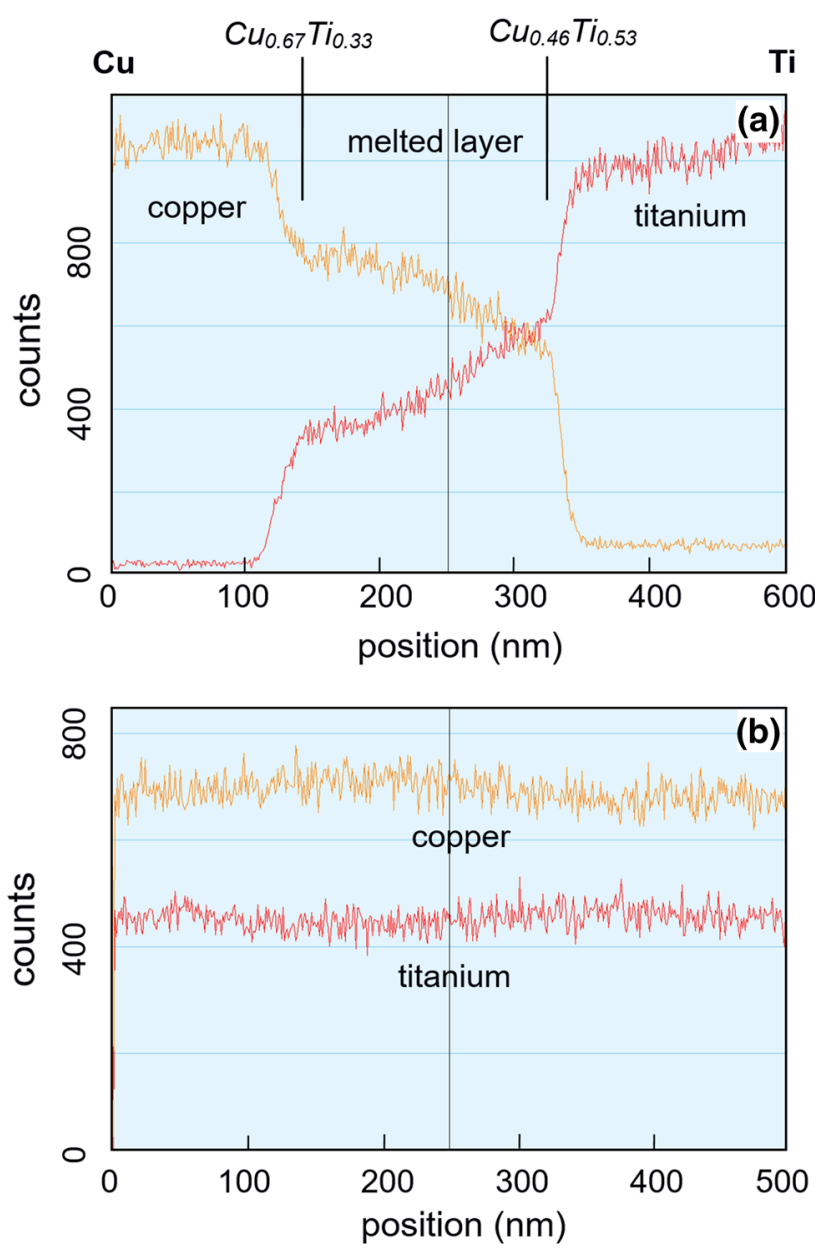

Fig. 12-TEM/EDX line scans and point analyses $(a)$ across and $(b)$ along the melt zone showing the distribution of $\mathrm{Cu}$ and Ti. (The line scans are marked in Fig. 10(a)). The clad manufactured at a detonation velocity of $2500 \mathrm{~m} \mathrm{~s}^{-1}$ and a stand-off distance of $9 \mathrm{~mm}$. The thin foil cut off from ND/RD section.

Table II. TEM/EDX Point Analysis of Chemical Composition Changes in Melt Zone (Layer)

\begin{tabular}{lcc}
\hline & \multicolumn{2}{c}{ At. Percent } \\
\cline { 2 - 3 } Point Number/Chemical Element & $\mathrm{Ti}(\mathrm{K})$ & $\mathrm{Cu}(\mathrm{K})$ \\
\hline Across the Melted Layer $(\mathrm{Cu} \rightarrow \mathrm{Ti})$ & & \\
1 & 32.5 & 67.5 \\
2 & 38.7 & 61.3 \\
3 & 47.0 & 53.0 \\
4 & 50.2 & 49.8 \\
5 & 53.4 & 46.6 \\
Along the Melted Layer & & \\
6 & 45.4 & 54.6 \\
7 & 46.4 & 53.6 \\
8 & 51.1 & 48.9 \\
9 & 46.7 & 53.3 \\
10 & 49.8 & 50.2 \\
11 & 43.4 & 56.6 \\
\hline \multicolumn{2}{l}{ Results correspond to line scans marked in Fig. $11(\mathrm{a})}$. \\
\hline
\end{tabular}

Results correspond to line scans marked in Fig. 11(a). the melting of the thin layer between the joined materials. This is contrary to some of the previous reports, where the interface with no observed melt layers using optical microscopy or SEM was usually defined as a pure metal/pure metal type and the mechanism responsible for its bonding was ascribed to adhesion of both plates. ${ }^{[20]}$ However, TEM reveals a thin reaction layer along the entire interface, which confirms the role of melting in creation of a "good quality" bond, and the validity of the hydrodynamic approach for joint formation during $\mathrm{EXW} .^{[50]}$

The concept that bonding is always achieved by short-time melting, followed by extremely rapid solidification of a thin layer along the contact interface is not new (Hammerschmidt and Kreye). ${ }^{[54]}$ The presence of a thin layer (composed of an amorphous and/or nanograined phase) was also documented experimentally in Zr700-carbon steel, ${ }^{[24]}$ Ta-stainless steel, ${ }^{[25]}$ and low carbon steel-low carbon steel clads. ${ }^{[36]}$

This also indicates that the single interfaces of pure metal/pure metal, as observed by optical microscopy, are in fact double interfaces of the pure metal/melt zone/ pure metal structure. Such a situation was also analyzed by Nakamura and Kikuchi ${ }^{[5]}$ who showed that the resistivity of the specimens increases by increasing the number of interfaces.

The above correlation between EXW parameters, interface waviness, and the number of melt zones appears consistent with that observed in multi-layered clads, where the strong waviness of the first interface changes smoothly to a flat-type in the next layers. ${ }^{[56]} \mathrm{At}$ the first interface, which is joined at the highest impact velocity and collision angle, the solidified melt zones are situated inside the wave vortexes and to a minor extent on the wave crests, whereas at successive interfaces, the melt zones take the form of a thin semi-continuous layer. This suggests that in multi-layered clads, the impact velocity rapidly decreases across consecutive layers. This also leads to an electrical conductivity gradient.

The influence of chemical composition on clad resistivity is ambiguous. It has been established that $\mathrm{Ti}$ addition increases (at room temperature) the electrical resistivity of the $\mathrm{Cu}$ alloy (compared with pure $\mathrm{Cu}){ }^{[57,58]}$ However, the observed drop in resistivity cannot only be assigned to the existence of melt zones with different chemical compositions since their volume fraction is relatively low (only a few percent). Therefore, the essential loss of electrical conductivity is caused by an enlargement of the contacting surface, new interfaces, strain hardening of parent plates, and the network of macro- and micro-cracks inside the melt zones.

\section{Formation of Severely Deformed Layers in Areas Near the Interface}

The influence of the density of defects in the crystal structure on the strength and electrical conductivity seems to be rather complex to analyze. On the one 


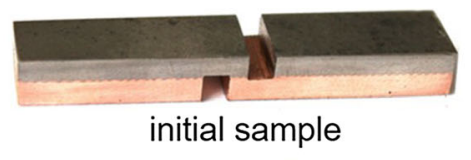

(a)

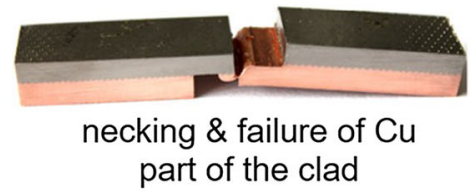

(b)

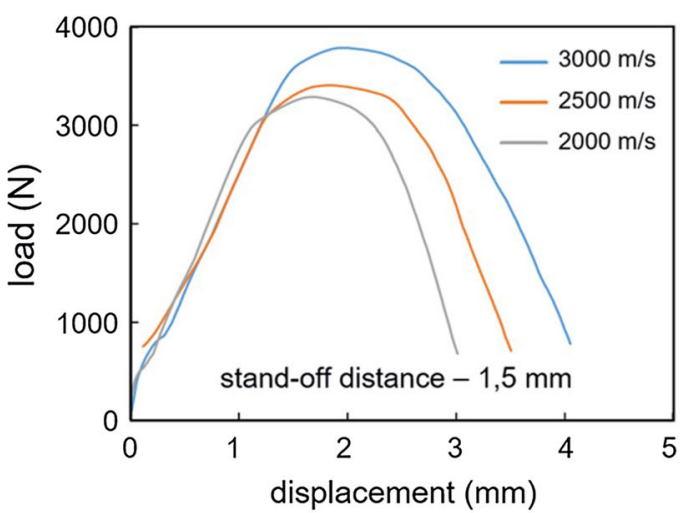

(c)

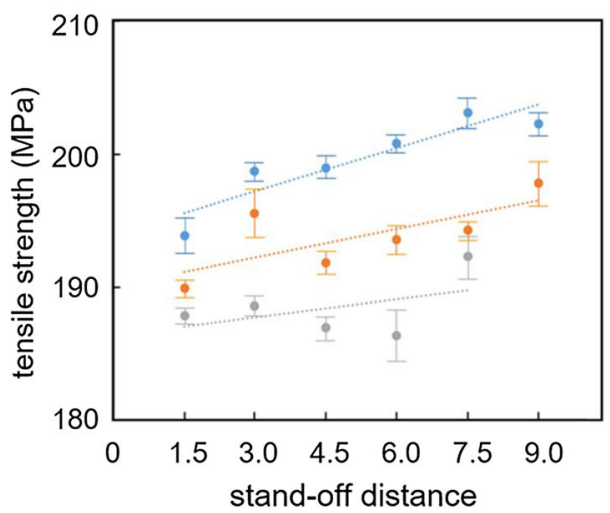

(d)

Fig. 13-Sample $(a)$ before and $(b)$ after the tensile-shear test showing necking and failure in Cu part of the clad. (c) Load-displacement curves for clads manufactures at detonation velocities ranged 2000 and $3000 \mathrm{~m} \mathrm{~s}^{-1}$ for stand-off distance of $1.5 \mathrm{~mm}$. (d) Plot showing dependency between ultimate strength and bonding parameters.

hand, the strain hardening of adjacent interface layers is considered to increase the strength properties of the clad but it decreases its electrical conductivity. ${ }^{[59]}$ This is because in the bonded state, these effects are caused by an increase of lattice defects, such as dislocations, vacancies, and/or grain boundaries, as discussed earlier for deformed $\mathrm{Cu}^{[47]}$ and $\mathrm{Ti}^{[60]}$ For example, in copper/ stainless steel clads, ${ }^{[19]}$ an increase in the microhardness near the interface and free surfaces is observed due to cold plastic deformation. Microhardness (strain hardening) increases in the lower part of the base plate due to collisions with the anvil, whereas the microhardness increase in the upper part of the flyer plate is due to the sudden shock of the explosive charge detonation. On the other hand, the recovery and recrystallization processes initiated during EXW can decrease the density of the structural defects in layers near the interface due to heat transfer from large melt zones towards strain-hardened layers. ${ }^{[23-25,52]}$ This, in turn, leads to an increase in electrical conductivity and a decrease in the strength. However, the influence of the softening processes on resistivity during EXW is tough to establish due to difficulties in the qualitative estimation of the heat transfer from the melt zones towards the severely deformed layers of the parent plates.

Another issue is the crystallographic texture, which is known to influence resistivity. Large plastic deformations cause the formation of specific texture components. ${ }^{[61]}$ Typically, the $<111>$ components exhibit the lowest electrical resistivity for fcc metals and alloys. The effect of the $\langle 111\rangle$ and $<100\rangle$ fiber-type texture formation on the electrical resistivity of copper wires has been discussed by Pavithra et al. ${ }^{[62]}$ and Moisy ${ }^{[47]}$ and they found no significant effect. On the other hand, Ueda et $a l .{ }^{[0]}$ showed that the electrical resistivity of cold-rolled cp-Ti is dependent on the formation of specific texture components. They reported that the resistivity along the c-axis of $\mathrm{Ti}$ was higher than that along other axes. However, to understand fully the texture effect on resistivity anisotropy, local texture measurements are required. 


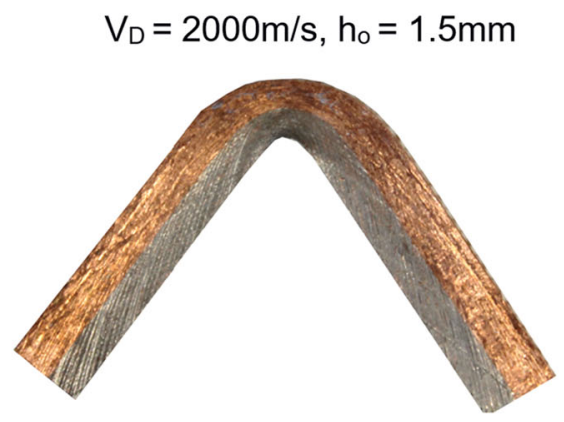

(a)

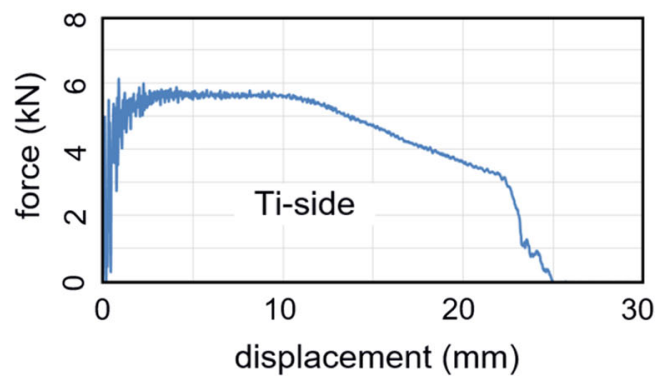

(c)

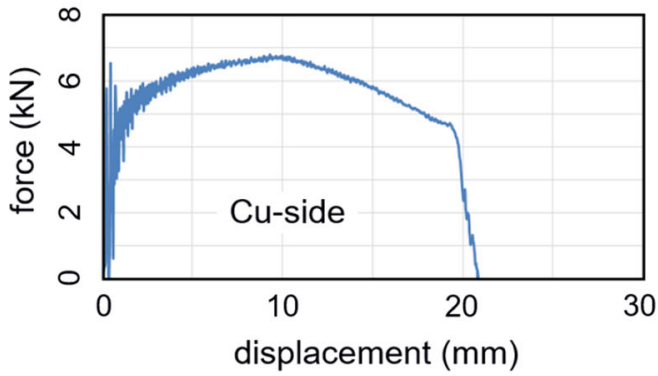

(e)

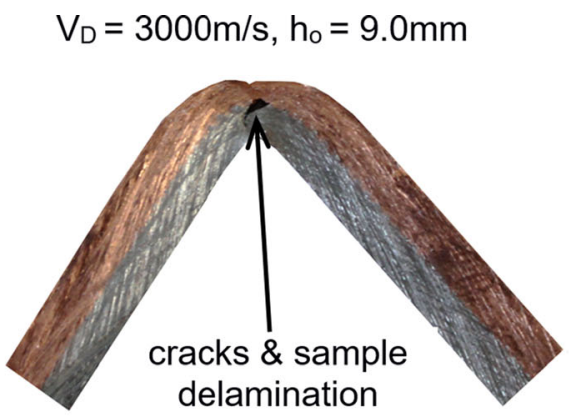

(b)

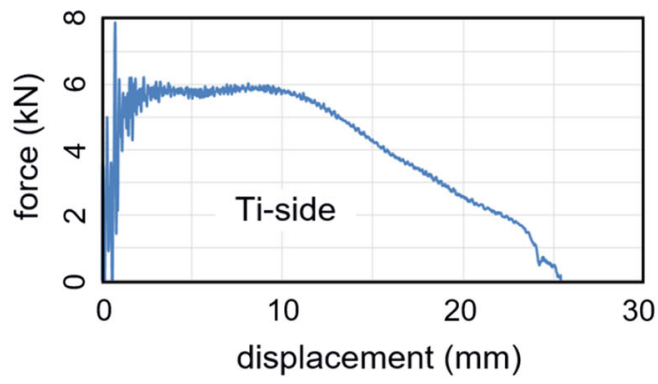

(d)

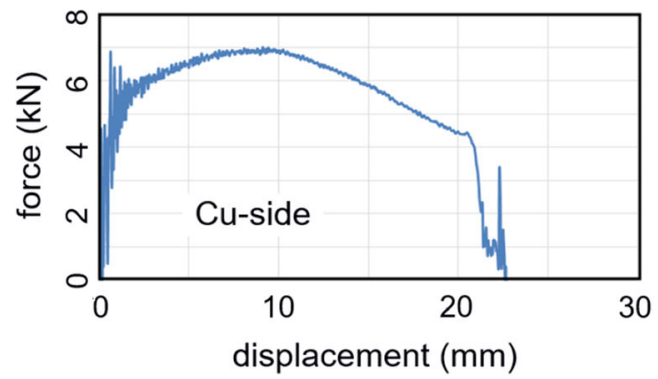

(f)

Fig. 14- $(a, b)$ View on the lateral plane of the sample deformed during dynamic bending test and corresponding the force-displacement characteristics, which reveal small differences depending on the convex side: $(c, e) \mathrm{Cu}$ side and $(d, f)$ Ti side. Sample cut out from the clad manufactured at detonation velocity and stand-off distance of (a, c, e) $2000 \mathrm{~m} \mathrm{~s}^{-1}$ and $1.5 \mathrm{~mm}(\mathrm{RGP}=0.18),(\mathrm{b}, \mathrm{d}, \mathrm{f}) 3000 \mathrm{~m} \mathrm{~s}{ }^{-1}$ and $9.0 \mathrm{~mm}$ $(\mathrm{RGP}=18.2)$.

\section{CONCLUSIONS}

In this study, sheets of $\mathrm{Ti}$ and $\mathrm{Cu}$ were bonded through EXW using a parallel plate arrangement. The clads were manufactured at stand-off distances between 1.5 and $9.0 \mathrm{~mm}$ and detonation velocities ranging from 2000 to $3000 \mathrm{~m} \mathrm{~s}^{-1}$. Under these conditions, a "good quality" clad satisfying all mechanical requirements was achieved. All bonds obtained were metallurgical in nature, and they were stronger than the weaker parent material $(\mathrm{Cu})$. The experimental results showed that increasing detonation velocities and stand-off distances increased the period and amplitude of the interface waves as well as the volume fraction of melt zones.
These changes were well-defined using coefficients such as RGP ("quantity" of melt zones) and BLF (length of interfaces between melt zones and parent metals). However, the clad conductivity decreased significantly as the bonding parameters increased. A rapid decrease in electrical conductance of the clad is due to an increase of the interface area, the occurrence of new interfaces between melt zones and parent materials, formation of a network of the macro/micro-cracks within the large melt zones, and strain hardening near the interface layers.

SEM observations have shown that large melt zones form just behind the wave crest and inside the wave vortexes. Furthermore, TEM analysis confirmed that the flat parts of the interface contain a thin reaction 

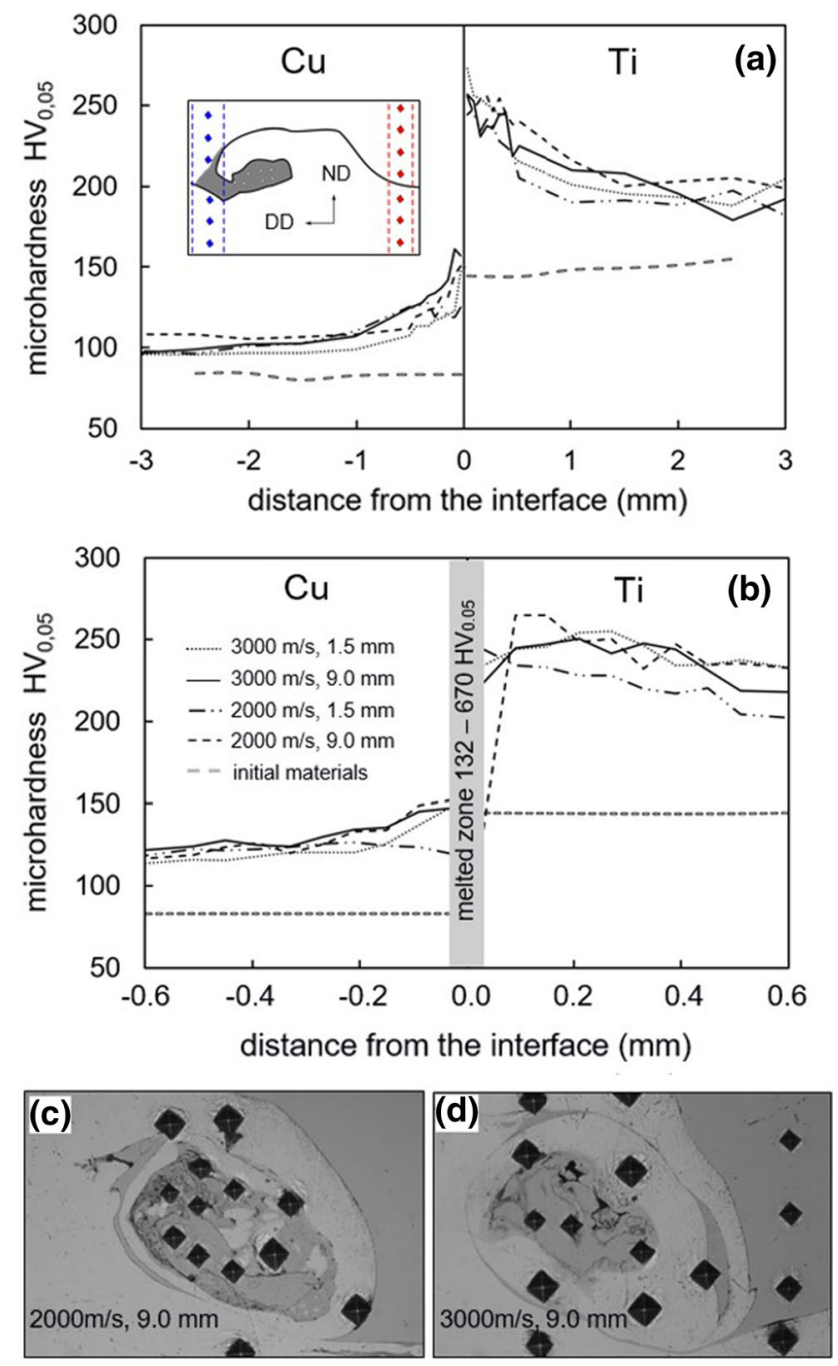

Fig. 15-Vickers microhardness changes on ND/RD section in explosively welded $\mathrm{Cu}$ and $\mathrm{Ti}$ sheets: $(a)$ "scan line" across the metal/metal-type interface - the whole clad thickness, (b) "scan line" across the metal/(melt area)-type interface. $(c, d)$ Optical microscopy micrographs showing indentations inside intermetallic inclusions and parent plates, for clads manufactured at stand-off distance of 9.0 $\mathrm{mm}$ and detonation velocity of (c) $2000 \mathrm{~m} / \mathrm{s}$, and (d) $3000 \mathrm{~m} / \mathrm{s}$.

layer of a few tens of nanometers. The present results prove that a proper EXW process always incorporates the melting of very thin surface layers. The presence of a thin layer of solidified melt confirms the crucial role of melting in the creation of a good quality bond.

SEM and TEM chemical composition measurements have shown that most of the phases which form within the melt zones do not appear in the equilibrium phase diagram. Only a small number of intermetallic phases such as $\mathrm{CuTi}_{3}, \mathrm{Cu}_{3} \mathrm{Ti}$, and $\mathrm{Cu}_{4} \mathrm{Ti}_{3}$ were uncovered using synchrotron radiation. It suggests that the central part of the areas inspected by EDS is a mixture of pure Ti and $\mathrm{Cu}$. Finally, this study opens the possibility to

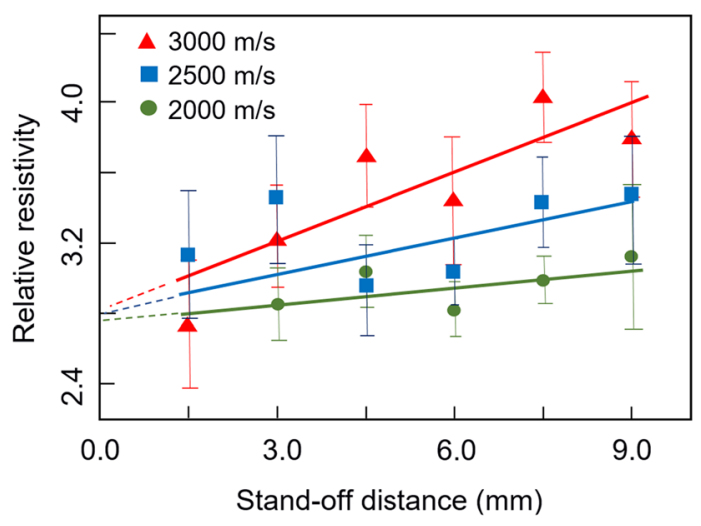

(a)

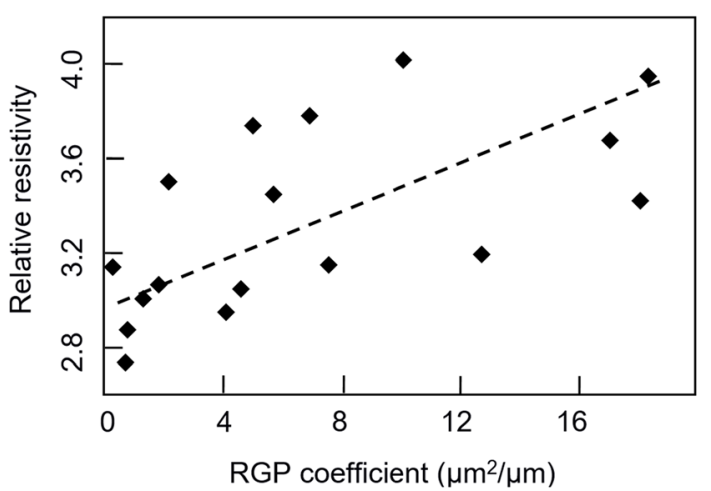

(b)

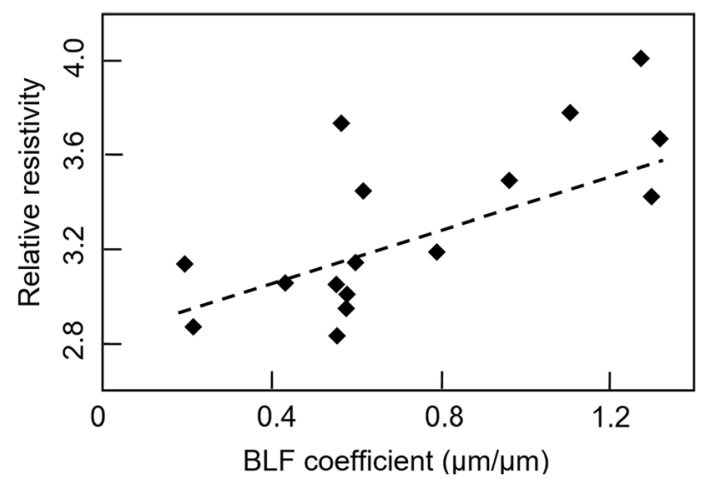

(c)

Fig. 16-Relative resistivity $v s$ stand-off distance and detonation velocity $(a), R G P(b)$ and $B L F(c)$ coefficients.

fabricate $\mathrm{Cu}$-Ti clads with optimized mechanical properties and well-controlled electrical resistivity.

\section{ACKNOWLEDGMENTS}

This work was supported by the National Science Centre (Poland), under grant nos.: UMO-2012/05/B/ ST8/02522 and UMO-2016/21/B/ST8/00462. Additional thanks also go to Dr. K. Berent (ACMIN, Krakow, Poland) for providing some of the SEM analyses. 


\section{OPEN ACCESS}

This article is distributed under the terms of the Creative Commons Attribution 4.0 International License (http://creativecommons.org/licenses/by/4.0/), which permits unrestricted use, distribution, and reproduction in any medium, provided you give appropriate credit to the original author(s) and the source, provide a link to the Creative Commons license, and indicate if changes were made.

\section{REFERENCES}

1. M. Yang, H. Ma, Z. Shen, and Y. Sun: Fus. Eng. Des., 2019, vol. 143, pp. 106-14.

2. M.-X. Xie, X.-T. Shang, L.-J. Zhang, Q.-L. Bai, and T.-T. Xu: Metals, 2018, vol. 8 (3), pp. 159-73.

3. K. Topolski, Z. Szulc, and H. Garbacz: J. Mater. Eng. Perform., 2016, vol. 25, pp. 3231-37.

4. F. Findik: Mater. Des., 2011, vol. 32, pp. 1081-93.

5. P. Corigliano, V. Crupi, E. Guglielmino, and A.M. Sili: Mar. Struct., 2018, vol. 57, pp. 207-18.

6. P. Corigliano, V. Crupi, and E. Guglielmino: Ocean Eng., 2018, vol. 160 (15), pp. 346-53.

7. Y. Kaya: Metals, 2018, vol. 8 (7), pp. 544-59.

8. S.M. Aceves, F. Espinosa-Loza, J.W. Elmer, and R. Huber: Int. J. Hydro. Energy, 2015, vol. 40 (3), pp. 1490-1503.

9. A. Sanjurjo, B.J. Wood, K.H. Lau, G.T. Tong, D.K. Choi, M.C.H. McKubre, H.K. Song, and N. Church: Surf. Cat. Technol., 1991, vol. 49, pp. 110-15.

10. L.Y. Demidenko and N.A. Onatskaya: Surf. Eng. Appl. Electrochem., 2008, vol. 44 (3), pp. 245-47.

11. K. Aydin, Y. Kaya, and N. Kahraman: Mater. Des., 2012, vol. 37, pp. 356-68.

12. J. Hemanth: Open J. Compos. Mater., 2017, vol. 7, pp. 105-16.

13. Y. Zhao, W. Wang, K. Yan, C. Liu, and J. Zou: J. Mater. Proc. Technol., 2018, vol. 257, pp. 244-49.

14. S. Guo, Y. Peng, X. Xu, C. Diao, J. Kong, T.-Y. Luo, K.-H. Wang, and Y. Zhu: Mater. Des., 2017, vol. 124, pp. 51-50.

15. S.D. Meshram, T. Mohandas, and G.M. Reddy: J. Mater. Proc. Technol., 2007, vol. 184 (1), pp. 330-37.

16. R. Kumar and M. Balasubramanian: Def. Technol., 2015, vol. 11 (1), pp. 65-75.

17. J.S. Lee, H. Son, I.H. Oh, C.S. Khan, C.H. Yun, S.C. Lim, and H.C. Kwon: J. Mater. Proc. Technol., 2007, vols. 187-188, pp. $653-56$

18. M. Hosseini and H. Danesh Manesh: Mater. Des., 2015, vol. 81, pp. $122-32$.

19. N. Kahraman and B. Gülenç: J. Mater. Proc. Technol., 2005, vol. 169 , pp. $67-71$.

20. Explosive Welding, Forming and Compaction, ed., T.Z. Blazynski, ed., Explosive Welding, Forming and Compaction, Applied Science Publishers LTD, New York, 1983.

21. V.I. Lysak and S.V. Kuzmin: in Explosive Welding of Metal Layered Composite Materials, B.E. Paton, ed., E.O. Paton Electric Welding Institute, Kiev, 2003.

22. I.A. Bataev, D.V. Lazurenko, S. Tanaka, K. Hokamoto, A.A. Bataev, Y. Guo, and A.M. Jorge, Jr: Acta Mater., 2017, vol. 135 , pp. $277-89$.

23. H. Paul, L. Lityńska-Dobrzyńska, and M. Prażmowski: Metall. Mater. Trans. A, 2013, vol. 44A, pp. 3836-51.

24. H. Paul, J. Morgiel, M. Faryna, M. Prażmowski, and M. Miszczyk: Int. J. Mater. Res., 2015, vol. 106 (7), pp. 782-92.

25. H. Paul, M.M. Miszczyk, R. Chulist, M. Prażmowski, J. Morgiel, A. Gałka, M. Faryna, and F. Brisset: Mater. Des., 2018, vol. 153, pp. $177-89$.

26. J. Song, A. Kostka, M. Veehmayer, and D. Raabe: Mater. Sci. Eng. A, 2011, vol. 528, pp. 2641-47.
27. D.V. Lazurenko, I.A. Bataev, V.I. Mali, A.A. Bataev, I.N. Milutina, V.S. Lozhlin, M.A. Esikov, and A.M.J. Jorge: Mater. Des., 2016, vol. 102, pp. 122-30.

28. S.R. Carpenter: in Shock Waves and High-strain-rate Phenomena in Metals, M.A. Meyers and L.E. Murr, eds., Plenum Press, New York, 1981, pp. 941-45.

29. H. Paul, M. Faryna, M. Prażmowski, and R. Banski: Arch. Metall. Mater., 2011, vol. 56, pp. 463-74.

30. R. Mendes, B. Ribeiro, and A. Loureiro: Mater. Des., 2013, vol. 51, pp. 182-92.

31. S.K. Godunov, A.A. Deribas, and N.S. Kozin: J. Appl. Mech. Tech. Phys., 1971, vol. 2 (3), pp. 398-406.

32. S.R. Reid and N.H.S. Sherif: J. Mech. Eng. Sci., 1976, vol. 18 (2), pp. 87-94.

33. D. Jaramillov, O.T. Inal, and A. Szecket: J. Mater. Sci., 1987, vol. 22 (9), pp. 3143-47.

34. S.A.L. Salem, S.T.S. Al-Hassani: in Shock waves and high strain rate phenomena in metals: concepts and applications. Meyers MA, Murr LE, eds., Proceedings of the International conference on metallurgical effects of high-strain-rate deformation and fabrication, Plenum Press, New York 1981, pp. 1003-18.

35. P. Manikandan, K. Hokamoto, M. Fujita, K. Raghukandan, and R. Tomoshige: J. Mater. Proc. Technol., 2008, vol. 195 (1-3), pp. $232-40$.

36. I.A. Bataev, S. Tanaka, Q. Zhou, D.V. Lazurenko, A.M. Jorge Junior, A.A. Bataev, K. Hokamoto, A. Mori, and P. Chen: Mater. Des., 2018, vol. 169, p. 107649.

37. D. Fronczek, J. Wojewoda-Budka, R. Chulist, A. Sypień, A. Kornewa, Z. Szulc, N. Schell, and P. Zieba: Mater. Des., 2016, vol. 91 , pp. $80-89$.

38. A. Durgutlu, H. Okuyucu, and B. Gulenc: Mater. Des., 2008, vol. 29 , pp. $1480-84$.

39. N. Kahraman, N. Gulenc, and F. Findik: J. Mat. Proc. Technol., 2005, vol. 171, pp. 241-49.

40. S.A.A. Akhbari Mousavi and P. Farhadi Sartanagi: Mater. Des., 2009, vol. 30 , pp. 459-68.

41. K. Hokamoto, A. Chiba, M. Fujita, and T. Izuma: Compos. Eng., 1995, vol. 5 (8), pp. 1069-79.

42. H. Paul, M.M. Miszczyk, A. Gałka, R. Chulist, and Z. Szulc: Arch. Metall. Mater., 2019, vol. 64, pp. 683-94.

43. G.G. Zu, X. Li, J. Zhang, and H. Zhang: J. Wuhan Univ. Technol. Mater. Sci. Ed., 2015, vol. 30 (6), pp. 1199-1203.

44. A.D. Tete, A.Y. Deshmukh, and R.R. Yerpude: Int. J. Eng. Technol., 2013, vol. 2 (3), pp. 259-65.

45. M. Prażmowski, D. Rozumek, and H. Paul: Eng. Fail. Anal., 2017, vol. 75 , pp. 71-81.

46. R. Chulist, L. Straka, A. Sozinov, T. Lippmann, and W. Skrotzki: Scr. Mater., 2013, vol. 68, pp. 671-74.

47. F. Moisy, A. Gueydan, X. Sauvage, A. Guillet, C. Keller, E. Guilmeau, and E. Hug: Mater. Des., 2018, vol. 155, pp. 366-74.

48. Z. Livne and A. Munitz: J. Mater. Sci., 1987, vol. 22, pp. $1495-1500$.

49. Q. Chu, M. Zhang, J. Li, and Ch. Yan: Mater. Sci. Eng. A, 2017, vol. 689 , pp. $323-31$.

50. B. Crossland: Explosive Welding of Metals and its Application, Clarendon Press, Oxford, 1982.

51. A. Durgutlu, B. Gulenc, and F. Findik: Mater. Des., 2005, vol. 26 (6), pp. 497-507.

52. B. Wronka: J. Mater. Sci., 2010, vol. 45, pp. 4078-83.

53. M.M. Miszczyk, H. Paul, J.H. Driver, and P. Drzymała: Acta Mater., 2017, vol. 125, pp. 109-24.

54. M. Hammerschmidt and H. Kreye:Microstructure and bonding mechanism in explosive welding in Shock Waves and High-Strain-Rate Phenomena in Metals, M.A. Murr and L.E. Murr, eds., Plenum Press, New York, 1981.

55. K. Nakamura and S. Kikuchi: J. Jpn. Inst. Metals Mater., 2008, vol. 72 (10), pp. 800-03.

56. H. Paul, Ł. Maj, M. Prażmowski, A. Gałka, M. Miszczyk, and P. Petrzak: Proc. Manuf., 2018, vol. 15, pp. 1391-98.

57. A.A. Eze, T. Jamiru, R. Sadiku, M.O. Durowoju, W.K. Kupaloti, I.D. Ibrachim, B.A. Abadele, P.A. Olubambi, and S. Diouf: $J$. Alloys Compd., 2018, vol. 736, pp. 163-71. 
58. J. Zhang and Y.C. Zhou: J. Mater. Res., 2008, vol. 23 (4), pp. $924-32$.

59. J.B. Liu, L. Meng, and Y.W. Zeng: Mater. Sci. Eng. A, 2006, vols. 435-436, pp. 237-44.

60. M. Ueda, K. Ota, and M. Ikeda: Mater. Trans., 2013, vol. 54, pp. $1650-54$.

61. R. Chulist, D.M. Fronczek, Z. Szulc, and J. Wojewoda-Budka: Mater. Charact., 2017, vol. 129, pp. 242-46.
62. C.L.P. Pavithra, B.V. Sarada, K.V. Rajulapati, M. Ramakrishna, R.C. Gundakaram, T.N. Rao, and G. Sundararajan: Cryst. Growth Des., 2015, vol. 15, pp. 4448-58.

Publisher's Note Springer Nature remains neutral with regard to jurisdictional claims in published maps and institutional affiliations. 